\title{
PENSAMIENTO Y CULTURA ESTRATÉGICA EN SEGURIDAD Y DEFENSA: BASES PARA LA CONSTRUCCIÓN DE UNA GRAN ESTRATEGIA DEL ESTADO ${ }^{1}$
}

Carlos Enrique Álvarez Calderón Carlos Giovanni Corredor Gutiérrez Omar Ferney Vanegas Rincón

\section{Introducción}

Es probable que exista un vacío intelectual en el arte de gobernar colombiano, ya que durante décadas pareciera costarle trabajo al Estado construir estrategias coherentes en seguridad y defensa de mediano y largo plazo. No obstante, los gobiernos de turno y sus Fuerzas Armadas lo han intentado parcialmente al tomar en consideración la procura del uso de algunos recursos nacionales para alcanzar ciertos objetivos, así como de la fuerza armada y no armada, de forma que aseguren el orden constitucional y la defensa del territorio. No obstante, la materialización de una 'Gran Estrategia' en documentos estratégicos, como una 'Estrategia de Seguridad Nacional' o un 'Libro Blanco de Defensa', son todavía tareas pendientes. En efecto, no existe una 'Gran Estrategia' que guíe al Estado colombiano en la definición de sus intereses nacionales y en la elaboración de un mapa de ruta que permita a la sociedad colombiana navegar por las aguas de un proceso de transición generacional en la concepción de seguridad y defensa. Más aún, en un contexto en el que

uno de los grandes desafíos que se cierne para Colombia en los próximos años, luego del acuerdo de paz firmado con una parte representativa de las Fuerzas Armadas Revolucionarias de Colombia (FARC), y posiblemente con el Ejército de Liberación Nacional (ELN), es evitar los fracasos que han experimentado, en otras partes del mundo, las actividades de consolidación de paz y reconstrucción de Estado. (Álvarez, 2017a, p. 307)

1 Este Capítulo del Libro hace parte del Proyecto de Investigación de la Maestría en Seguridad y Defensa Nacionales, titulada "Desafíos y Nuevos Escenarios de la Seguridad Multidimensional en el Contexto Nacional, Regional y Hemisférico en el Decenio 2015-2025”, el cual hace parte del Grupo de Investigación Centro de Gravedad de la Escuela Superior de Guerra "General Rafael Reyes Prieto", reconocido y categorizado en (A) por COLCIENCIAS, con el código COL0104976. 
El fin de las guerras y la consolidación de la paz serían procesos de transición que demandan una estrategia integral en materia de seguridad y bienestar socioeconómico, ya que el éxito militar en sí mismo es insuficiente para lograr la victoria. La historia contiene numerosos ejemplos de ejércitos que ganaron todas las batallas y, sin embargo, perdieron la guerra debido a una estrategia defectuosa. En Vietnam, por ejemplo, el ejército de los Estados Unidos derrotaría al vietcong y al Ejército de Vietnam del Norte en la mayoría de los enfrentamientos que sostuvieron; no obstante, los Estados Unidos eventualmente perderían la guerra, porque los líderes civiles y militares nunca entendieron la naturaleza compleja del conflicto que estaban librando.

Sería axiomático que la política impulse la estrategia. ${ }^{2} \mathrm{Y}$ si bien la política impulsa la estrategia, las capacidades y limitaciones del instrumento militar también moldean la política. Sin embargo, los responsables de la formulación de políticas a menudo malinterpretan la relación. Por ende, en un mundo globalizado en donde se presenta una mayor demanda de los recursos escasos, se ha vuelto un imperativo clarificar la relación entre fines y medios, por lo que muchos Estados ahora se preocupan no solo por la forma más efectiva, sino también por la forma más eficiente de lograr los objetivos nacionales deseados. En este orden de ideas, se considera que la 'Gran Estrategia' es un enfoque conceptual que puede ayudar a asignar de mejor manera los recursos escasos a problemas complejos. Sin embargo, es difícil pensar, diseñar o evaluar grandes estrategias si el propio término no se entiende correctamente. Si bien las estrategias son formuladas por individuos, usualmente son implementadas por medio de las burocracias. Como resultado, en ocasiones una buena estrategia podría llegar a fallar en la ejecución, a menos que todos los involucrados en su diseño e implementación tengan un entendimiento común de la teoría estratégica.

Si bien la estrategia ha sido una preocupación de los generales y de los estadistas durante milenios, el término ha perdido en la actualidad su única asociación con la guerra, usándose de manera más amplia en casi todas las actividades humanas, desde los negocios hasta los deportes. En efecto, como el concepto ha evolucionado con el tiempo, ha sido apropiado por una amplia gama de actores, muchos de los cuales han tenido poco o nada que ver con la seguridad nacional. De acuerdo a Strachan (2013), la "palabra [estrategia] ha adquirido una universalidad que le ha robado el significado, y la ha dejado solo con banalidades" (p. 34). Hoy

2 Vale la pena enfatizar que la primacía de la política se aplica no solo a los Estados, sino también a otros actores estratégicos. 
en día los gobiernos tienen estrategias para abordar los problemas en la educación, la salud pública, la economía, etc., mientras que las compañías publicitarias tienen estrategias para comercializar bienes y servicios.

Pero los estudios estratégicos no serían estudios comerciales, ni la estrategia sería un sinónimo de la política, a pesar de que la estrategia incorporaría más que solo el estudio de guerras y campañas militares. La estrategia, en su concepción original, sería entonces la aplicación del poder militar para lograr objetivos políticos, o, más específicamente, la teoría y la práctica del uso y la amenaza del uso de fuerzas organizadas con fines políticos (Gray, 1999).

\section{Los estudios estratégicos}

Los estudios en estrategia serían parte de los estudios en seguridad y defensa, así como estos serían parte de la disciplina de las Relaciones Internacionales, que a su vez haría parte de la Ciencia política (figura 1). Por ende, los estudios estratégicos no podrían considerarse como una disciplina en sí misma, ya que son un campo de estudio que ha dependido incluso de las artes, las ciencias exactas y las ciencias sociales para sus ideas y conceptos.

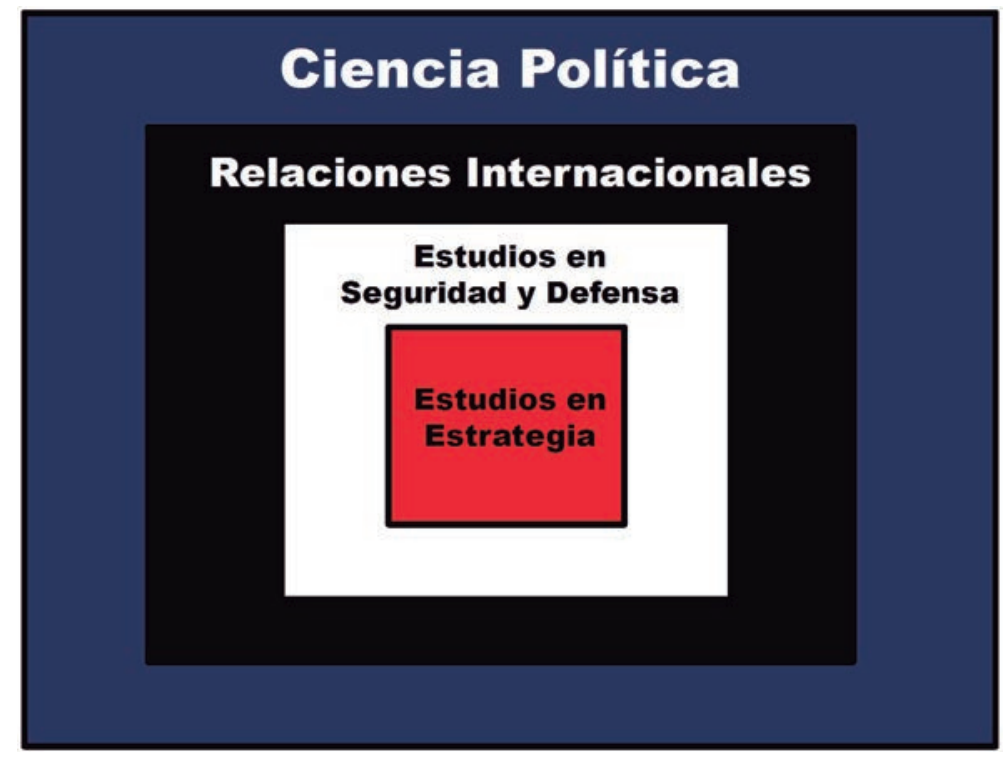

Figura 1. Relación entre estrategia, estudios en seguridad, relaciones internacionales y la ciencia política.

Fuente: elaboración propia. 
En efecto, la estrategia se estudiaría mejor desde una perspectiva interdisciplinaria. En virtud de lo anterior, para comprender las dimensiones de la estrategia, sería útil conocer sobre política, ${ }^{3}$ economía, ${ }^{4}$ psicología y sociología, ${ }^{5}$ geopolítica, ${ }^{6}$ historia militar, ${ }^{7}$ inteligencia estratégica ${ }^{8}$ y tecnología, ${ }^{9}$ entre otros.

$\mathrm{Si}$ se toma en cuenta que los pensadores estratégicos que han contribuido a los estudios estratégicos provienen de diferentes disciplinas, no sorprende observar que los estudios estratégicos han sido testigos de un debate continuo sobre su metodología. Bernard Brodie, quien más que nadie colaboraría en establecer los estudios estratégicos como un ámbito de estudio académico después de la Segunda Guerra Mundial, inicialmente argumentaría que la estrategia debería estudiarse científicamente. En este sentido, pidió un enfoque metodológico para el estudio de la estrategia similar al adoptado por la economía, con el argumento de que la estrategia debería abordarse como una ciencia instrumental para resolver problemas prácticos (Brodie, 1959).

Sin embargo, como el propio Brodie más tarde reconocería, el entusiasmo por la ciencia que había ayudado a promover llevaría a que los estudios estratégicos desarrollaran un sesgo cientificista en la década de los cincuenta. Es decir, la conceptualización de la estrategia, utilizando modelos y teorías económicas, se había llevado más allá de lo que el propio Brodie esperaba, evidenciado por la sorprendente falta de sentido político y la ignorancia de la historia diplomática y militar entre aquellos que escribían sobre estrategia. Asimismo, el enfoque académico para el estudio de la estrategia también generaría inquietudes sobre el descuido sobre cuestiones relacionadas a las operaciones militares, ya que, a medida que los estudios estratégicos se desarrollaron a fines de la década de los cuarenta, los analistas civiles llegarían a dominar el campo de los estudios estratégicos.

En la década de los ochenta, sin embargo, había una sensación creciente de que muchos de los estrategas civiles en departamentos universitarios y tanques de

3 Ver: Machiavelli, 1531; Hobbes, 1651; Montesquieu, 1752; Brodie, 1973; Creveld, 1991; Smith, 2005; Diebel, 2007.

4 Ver: Ricardo, 1684; Marx, 1887; Keynes, 1936; Porter, 1998; Lynch, 2006.

5 Ver: Neibuhr, 1932; Waltz, 1959; Waltzer, 1978 ; Fernandez-Osorio, Latorre Rojas y Mayorga Zarta, 2018.

6 Ver: Ritter, 1865; Reclus, 1905; Mahan, 1894; Ratzel, 1903; Mackinder, 1904; Kjellén, 1916; Fairgriebe, 1917; Mackinder, 1919; Vidal, 1921; Douhet, 1921; Strausz-Hupé, 1942; Spykman, 1944; Haushofer, 1975; Gray y Sloan, 1999; Buzán y Waever, 2003; Cohen, 2009.

7 Ver: Fontaine, 1983; Delbrück, 1985; Parker, 2010; Boot, 2013.

8 Ver: Kent, 1966; Johnson, 2003; Sullivan; 2007; Betts, 2007.

9 Ver: Petroski, 1982; Creveld, 1989; MacKenzie, 1990. 
pensamiento académicos, estaban ignorando las capacidades y limitaciones de las unidades y operaciones militares en sus análisis y teorías. La ciencia militar se había convertido en una disciplina perdida, razón por la cual, para una nueva clase de estrategas, la realidad de los problemas operativos tendría que regresar a sus estudios. Como la estrategia proveería el puente entre medios militares y fines políticos, los estudiantes de estrategia requerirían conocimientos tanto en política como en operaciones militares. En efecto, Betts sugeriría que si la estrategia consistía en la integración entre las políticas y las operaciones, aquella debería estar diseñada no solo por soldados políticamente sensibles, sino también por civiles con sensibilidad militar (Betts, 1997). Por tanto, los estudios estratégicos requerirían también la ilustración de ámbitos relacionados con estrategia total, ${ }^{10}$ estrategia global, ${ }^{11}$ estrategia general o conjunta ${ }^{12}$ y estrategia militar operativa. ${ }^{13}$

A raíz de las preocupaciones anteriormente descritas, concernientes a la falta de conocimiento en temas operacionales por parte de los estrategas civiles, se reviviría un interés entre los estudiosos de la estrategia por comprender los diferentes elementos o 'dimensiones' de esta. Clausewitz (1989) argumentaba que "todo en estrategia resulta muy simple, pero no por ello muy fácil” (p. 296). Es decir, la estrategia consistiría de elementos morales, físicos, matemáticos, geográficos y estadísticos. De manera similar, Howard (1983) se referiría a las dimensiones sociales, logísticas, operacionales y tecnológicas de la estrategia. Esta noción de la estrategia, consistente en un conjunto amplio, complejo e interdependiente de dimensiones, también sería abordado por Gray (1999), al identificar tres categorías principales: "política y sociedad", "preparación para la guerra" y la "propia guerra". A estas corresponderían 17 dimensiones de la estrategia: para la primera categoría “política y sociedad”, se encontrarían las dimensiones de gente, sociedad, cultura, política y ética; para la segunda categoría, "preparación para la guerra”, se encon-

10 Ver: Sun Tzu, 2012; Machiavelli, 1531; Clausewitz, 1989; Ludendorff, 1935; Toynbee, 1950; Tse-Tung, 1954; Schmitt, 1963; André, 1964; Garthoff, 1966; McNamara, 1968; Bouthoul, 1970; Collins, 1973; Freedman, 1981; Kissinger, 1984; Brams y Kilgour, 1988; Kahn, 1989; Lind et. al. 1989; Liang y Xiangsui, 2002; Aron, 2004; Dufort, 2017).

11 Ver: Kahn y Wiener, 1969; Lacoste, 1976; Toffler, 1984; Kennedy, 1987; Wallerstein, 1991; Fukuyama, 1992; Huntington, 1997; Gallois y Dupuy, 2000; Lempert, Popper y Bankes, 2003; Friedman, 2009.

12 Ver: Bernhardi, 1916; Foch, 1920; Falls, 1961; Mead, 1968; Collins, 1973; Jomini, 1977; Lawrence, 1935; Schelling, 1960; Rattenbach, 1979; Sokolovski1, 1981; Castex, 1994; Brzezinski, 1997; Luttwak, 2001; Howard, 2009. Fernandez-Osorio, Cufiño-Gutierrez, Gomez-Diaz y Tovar-Cabrera, 2018.

13 Ver: Weygand, 1938; Brodie, 1944; Ailleret, 1950; Goerlitz, 1953; Lidell Hart, 1954; Craig, 1955; Douhet, 1955; Aranda, 1957; Osgood, 1957; Crozier, 1960; Lacouture, 1966; Kolko, 1968; Giap, 1970; Lidell Hart, 1970; Keegan, 1971; Moss, 1972; Beaufre, 1978; Rattenbach, 1979; Hackett, 1979; Chaliand, 1982; Minh, 1984; Delbruck, 1985; Glantz, 1991; Howard, 1993; Eisenhower, 1997; Churchill, 2002; De Gaulle, 2015, entre otros. 
trarían las dimensiones económica y de logística, organización, administración militar, información e inteligencia, teoría estratégica y doctrina, y tecnología; para la última categoría, la "propia guerra", se identificarían las operaciones limitadas, comando, geografía, fricción, el adversario y el tiempo. Al igual que Clausewitz, Gray establecería que no tener en cuenta alguna de estas dimensiones haría incompleto cualquier estudio de la estrategia.

Una de aquellas dimensiones es la 'Teoría Estratégica', que proporciona un útil sistema lógico-deductivo para abordar el fenómeno de la guerra y otros términos asociados (conflicto, competencia, etc.). En este orden de ideas, la lógica de la guerra y de la estrategia sería universal y válida en cualquier momento y en cualquier lugar (Mahnken, 2016). Ello, en virtud de que la guerra es una actividad humana y la naturaleza humana ha permanecido inmutable con relación al progreso material, debido a que las mismas emociones que motivarían a los seres humanos en épocas primitivas continuarían ejerciendo una poderosa influencia en el presente (Álvarez, 2018).

Los actos humanos no vienen de la nada, ni vienen de la naturaleza del medio ambiente. Proceden de las creencias que las personas poseen (y optan por poseer), en relación con su medio ambiente, sus quejas, temores, expectativas, y así sucesivamente. (Álvarez et al., 2017, p. 153)

A pesar de que teóricos de la estrategia como Carl von Clausewitz y Sun Tzu escribirían sus obras en contextos históricos y perspectivas culturales totalmente diferentes (lo que llevaría a cada uno a abordar la estrategia de manera particular), el fenómeno de estudio que abordarían, es decir, la guerra, sería la misma. Es el carácter de la guerra y la conducción de la guerra (cómo se lucha, quiénes la luchan y qué se espera obtener de la lucha), no la naturaleza, las que han mutado en el tiempo. Por ende, la teoría estratégica proveería un conjunto de fundamentos conceptuales para la profunda comprensión de la guerra al ofrecer una caja de herramientas que facilita el análisis en asuntos de guerra y paz. En otras palabras, comprender la teoría estratégica les proporcionaría a los estudiantes y profesionales en estrategia una serie conceptos e interrogantes necesarios para avanzar con profundidad en los estudios estratégicos en seguridad y defensa.

\subsection{La tradición del realismo clásico en los estudios estratégicos}

La mayoría de los estrategas contemporáneos en Occidente pertenecerían a la misma tradición intelectual y compartirían un conjunto de suposiciones sobre la naturaleza de la política internacional y el tipo de razonamiento que mejor podría 
llegar a lidiar con los asuntos políticos y militares. Este conjunto de suposiciones es denominado a menudo 'realismo'.

"Realismo" es un término que se usa en una variedad de formas en muchas disciplinas diferentes. En filosofía, es una teoría ontológica opuesta al idealismo y el nominalismo. El "realismo científico" es una filosofía de la ciencia que se opone de diversas maneras al empirismo, el instrumentalismo, el verificacionismo y el positivismo. El "realismo" en la literatura y el cine se opone al romanticismo y los enfoques “escapistas”. En Relaciones Internacionales, el realismo político es una tradición de análisis que enfatiza los imperativos que enfrentan los Estados para perseguir una política de poder del interés nacional. (Donnelly, 2005, p. 29)

Y si bien existirían diferencias entre los propios realistas, hay ciertos puntos de vista y suposiciones con los que la mayoría estaría de acuerdo, en particular con respecto a la naturaleza humana, la anarquía y el poder, así como del derecho internacional, la moralidad y las instituciones.

Con relación a la naturaleza humana, la mayoría de los realistas clásicos son pesimistas, ya que a pesar que los seres humanos serían capaces de esgrimir actos de generosidad, gentileza y cooperación, el egoísmo y el orgullo inherentes a la condición humana los haría proclives al conflicto, la violencia y la maldad. En consecuencia, una de las principales tragedias de la naturaleza humana, según el realismo, es que estas tendencias destructivas nunca podrían llegar a erradicarse por completo, debido su carácter innato. Como el realismo no es una teoría normativa, en cuanto pretendería ofrecer una solución para la erradicación de la violencia en el mundo, si ofrecería una manera de hacer frente a la siempre presente amenaza de conflicto, mediante el uso de estrategias para minimizar la probabilidad y la gravedad de la violencia en el ámbito internacional. Por ende, en un sistema anárquico, la única moneda de valor cuando la seguridad del Estado estuviese amenazada, sería para el realismo, el poder (Baylis y Wirtz, 2016).

Frente a la anarquía y el poder, y partiendo de una concepción pesimista de la naturaleza humana, los realistas considerarían que fenómenos como la guerra y el conflicto serían endémicos en la política mundial, lo que llevaría a los Estados (sujetos de análisis preeminentes en la tradición realista) a una competencia implacable en la esfera internacional. Empero, a diferencia de la manera en que se manejarían los conflictos interestatales, los conflictos interestatales serían más complejos de resolver, debido a la inexistencia de una autoridad supranacional facultada para la creación de las condiciones de justicia y Estado de derecho. Por lo tanto, en ausencia de un gobierno mundial, los Estados adoptarían un enfoque de autopre- 
servación para la garantía de sus intereses y, especialmente, su seguridad, reservándose el derecho de usar la fuerza letal para lograr sus objetivos.

Por último, con referencia a 'derecho internacional, moralidad e instituciones', los realistas considerarían que estos tienen un rol limitado en el sistema internacional, por cuanto en ausencia de un gobierno supranacional los Estados aceptarían ciertas leyes cuando les convenga, pero las ignorarían cuando sus intereses se encuentren amenazados. Es decir, cuando los Estados quisieran romper las reglas habría muy poco que les impidiera hacerlo, aparte de la fuerza compensatoria. Del mismo modo, los realistas no creerían que las consideraciones morales podrían llegar a limitar significativamente el comportamiento de los Estados.

A pesar de que los fundamentos filosóficos compartidos han ayudado a darles a los estrategas coherencia intelectual, muchos supuestos realistas han sido sometidos a una feroz crítica por parte de otras tradiciones de pensamiento en relaciones internacionales. En efecto, los críticos de los estudios estratégicos afirmarían que los estrategas se encontrarían obsesionados con el conflicto y el uso de la fuerza, insuficientemente preocupados por cuestiones éticas, con una orientación Estadocéntrica y, por ende, susceptibles a un enfoque teórico estrecho (Gray, 1982). Argumentarían que debido a que los estrategas se enfocan en el rol del poder militar, tenderían a estar solamente preocupados por la violencia y la guerra, ignorando así los aspectos más cooperativos y pacíficos de la política mundial.

Sin embargo, los estrategas se enfocan en la tarea de crear estrategias nacionales efectivas o iniciativas internacionales para garantizar la seguridad nacional e internacional, lo que implica contemplar tanto instrumentos militares como económicos, diplomáticos y culturales. Lo cierto es que, ante las críticas antes señaladas, se han dado numerosos intentos de ampliar la base teórica de los estudios estratégicos, como se evidencia en los trabajos de Klein (1994), Katzenstein (1996) y Gray (1999).

\section{Fundamentos en teoría estratégica}

Los académicos y los profesionales de la estrategia requieren un conjunto de términos con un uso y una comprensión comunes para tratar problemas complejos. Sin embargo, tal vez, debido a la naturaleza aplicada del campo, estos términos y los conceptos que los respaldan a menudo no atraen la atención que merecen. En este sentido, no existe en la actualidad una definición comúnmente aceptada de la 'estrategia', ya que el concepto ha probado ser notoriamente difícil de definir. En consecuencia, existirían numerosas definiciones de 'estrategia', y cada una podría 
llegar a ubicarse en una temporalidad y contexto teórico particulares. Por ejemplo, Carl von Clausewitz definiría la estrategia como "el empleo de la batalla para la consecución del objeto de la guerra” (Rapaport, 1968, p. 241), mientras que Napoleón Bonaparte como "el arte de hacer uso del tiempo y el espacio" (Jablonsky, 1993, p. 11). Por su parte, Basil Henry Liddell-Hart afirmaba que "la estrategia es el arte de distribuir y aplicar medios militares para el cumplimiento de la política" (Freedman, 1981, p. XVII), y Vladímir Ilich Uliánov, Lenin, como "la elección de los puntos de aplicación de las fuerzas" (Celelier, 1979, p. 104).

Las definiciones anteriores restringirían la palabra estrictamente a los asuntos militares, a pesar de que en la práctica la estrategia operaría en una esfera más amplia. Es más, tales enfoques conceptuales desvían la investigación hacia factores objetivos, lo que implica desconocer que la estrategia involucraría pasiones, valores y creencias humanas, algunas de las cuales podrían, incluso, llegar a ser cuantificables. En efecto, la estrategia sería un proceso, una adaptación constante a las condiciones y circunstancias cambiantes en un mundo donde dominarían la suerte, la incertidumbre y la ambigüedad. Un mundo en el que las acciones, las intenciones y los propósitos de otros participantes permanecerían a la sombra, entorpeciendo la sabiduría y la intuición del estratega más hábil.

Por lo tanto, en términos esenciales y para objeto de esta obra, la 'estrategia' es la forma como se haría algo, es decir: la 'estrategia' sería un plan de acción. Más precisamente, la 'estrategia' sería un plan para aplicar unos recursos con el fin de lograr unos objetivos, por lo que sería inseparable de la relación en el pensamiento y la acción entre medios y fines, recursos y objetivos, poder y propósito, capacidades e intenciones, en cualquier esfera de la actividad humana. En este sentido, el concepto tendría una comprensión similar tanto en el ámbito militar como en el corporativo. Brzezinski (1988) se referiría a la estrategia como "la aplicación global y planificada de medidas para alcanzar un objetivo central o ventajas fundamentales de tipo militar" (p. 10). Por su parte, Porter (1996) la definía como la creación de una posición única y valiosa, que implica un conjunto diferente de actividades" (p. 68).

En definitiva, sin importar la definición, la esencia del concepto de "estrategia” descansaría en el reino de las consecuencias de la acción de los resultados futuros. Por ende, la estrategia sería más un arte que una ciencia, si se considera que se ocuparía más del reino de lo probable, que del reino de las certezas. Si bien una adecuada estrategia mejoraría las posibilidades del éxito estratégico, no garantizaría necesariamente la victoria, tomando en cuenta que el rango de elección estratégica estaría inevitablemente limitado por la realidad material y política. No obstante, el hecho de que la estrategia sea más un arte que una ciencia no significaría que no se pueda estudiar sistemáticamente. 
Es en este orden de ideas que la teoría estratégica proporcionaría la base conceptual para una adecuada comprensión de la guerra, si se entiende la guerra como "un estado de conflicto colectivo y organizado, que puede desarrollarse a través de hostilidades violentas y no violentas" (Álvarez et al., 2017, p. 152). En este sentido, cualquier discusión sobre la estrategia debería comenzar con la comprensión de la guerra, ya que es el contexto político de la guerra o la competencia, y no la identidad de quienes lo realizan, su característica más importante. La estrategia consistiría en hacer que la fuerza militar, económica o diplomática sea utilizable con fines políticos. En otras palabras, si la táctica consistiría en el empleo de las tropas en la batalla y el arte operacional en la realización de las campañas, entonces la estrategia trataría del uso de distintos medios (militares, económicos, culturales, tecnológicos, etc.), para el cumplimiento de los fines de la política. Sería el vínculo esencial entre los objetivos políticos y la fuerza militar, económica o diplomática, es decir, entre fines y medios (Mahnken, 2016).

Según Earle (1943), la estrategia sería en todo momento un elemento inherente a la política estatal. Así las cosas, la teoría estratégica ofrecería un conjunto de herramientas que posibilitan el pensamiento estratégico para el análisis de fenómenos relacionados con la guerra y la paz. A lo largo de la historia, los Estados han formulado e implementado estrategias para competir con sus rivales en tiempos de guerra y en tiempos de paz, como lo atestiguarían los casos de Atenas y Esparta en el siglo III a. C.; Francia, Estados Unidos y Gran Bretańa en el siglo XIX y principios del siglo xx; los Estados Unidos, Alemania y Japón durante la primera mitad del siglo xx; los Estados Unidos y la Unión Soviética durante la segunda mitad del siglo xx; China y los Estados Unidos en el siglo XxI. Algunos, como la competencia anglo-alemana, conducirían eventualmente a las dos guerras mundiales, mientras que otros, como la competencia entre los Estados Unidos y la Unión Soviética, generarían conflictos en la periferia y una inquietante 'paz armada' entre los actores centrales. La actual competencia estratégica entre Estados Unidos y China, si bien pacífica en términos militares, vive en la actualidad una intensa guerra comercial que podría llegar a conducir a hostilidades violentas.

\subsection{Los orígenes militares de la teoría estratégica}

El término 'estrategia' se deriva del latín strateğa, que a su vez procede de dos términos griegos: stratos (ejército) y agein (conductor o guía). Empero, 'estrategia' (strategie en francés, strategia en italiano, strategy en inglés) no sería una palabra que algún griego antiguo hubiese llegado a utilizar; su concepción moderna sería una derivación del término clásico bizantino strategos (general). Por lo tanto, el equi- 
valente griego de 'estrategia' pudo haber sido strategike episteme (conocimiento del general) o strategon sophia (sabiduría del general), razón por la cual el significado primario de 'estrategia' podría haber sido, en un principio, el arte de dirigir las operaciones militares.

De acuerdo con Heuser (2010), esta primera concepción de 'estrategia' estaba más cerca de lo que ahora se entiende por 'táctica'. Cognates ${ }^{14}$ como strategicos, que se evidencian en títulos de obras como el Strategikon de Mauricio (Dennis, 1984), tienen una connotación didáctica. Por el contrario, Strategemata, el título griego de la obra latina escrita por Frontino, reúne una compilación de estratagemas (strategema) o trucos y artimańas de guerra. Más comúnmente utilizado por los griegos, desde Aeneas en el siglo IV a. C. a Leo VI en el siglo IX d. C., sería la taktike techne, que describiría un cuerpo completo de conocimiento en la conducción de la guerra, desde el suministro a la retórica exhortatoria, incluidas tanto técnicas y tácticas adecuadas como la práctica diplomática (Luttwak, 2001). La taktike techne, o más bien su traducción latina ars bellica (de uso común en la época romana), resurgiría en 1518 en la obra Dell'arte della guerra de Maquiavelo, extendiéndose ampliamente en otros idiomas europeos: kriegskunst, art de guerre, art of war. Por ende, el término moderno 'estrategia' solo vendría a ser usado en Occidente hacia finales del siglo viII d. C., a partir de la obra del emperador bizantino Leo VI (Dennis, 2010).

\section{I. I El PUNTO de partida: antigua Grecia}

Sin embargo, no sería incorrecto rastrear los orígenes de la estrategia en Occidente hasta la antigua Grecia. Hacia el año 508 a. C., se formarían en Atenas diez nuevas divisiones tribales, cada una dirigida por un strategos elegido entre los ciudadanos. De acuerdo con Cummings (1995),

la creación del puesto de strategos reflejaba una mayor complejidad en la toma de decisiones militares. La guerra había evolucionado hasta un punto en que la victoria ya no dependía tan solo de las hazañas de individuos heroicos, sino también de la coordinación de muchas unidades distintas de hombres que luchaban en formaciones cerradas. (p. 23)

Los strategos no solo se seleccionarían por su sabiduría, sino también por su experiencia en el campo de batalla. Cummings (1995) ha descrito que la 'estrategia' en la sociedad griega del siglo $\mathrm{v}$ a. C. se basaba en el liderazgo colectivo responsable de las decisiones en nombre de la comunidad y sugirió que sus roles eran tener una

14 En lingüística histórica se llamarían cognados a aquellos términos con un mismo origen etimológico, pero con distinta evolución fonética y, usualmente, distinta semántica. 
visión, articular esta visión de manera efectiva y comunicarla a los ciudadanos para su aprobación. En efecto, Pericles, un famoso stratego de mediados del siglo v a. C., consideraba que las tareas del líder estaban basadas en la construcción, articulación y comunicación de una visión. Tucídides registraría ejemplos de oratoria de estrategas que intentarían convencer a la población de su curso de acción sugerido, y la respuesta de Pericles al ultimátum espartano podría ser una apreciación magistral de la situación política y militar de la época.

Por lo tanto, en el momento de la guerra del Peloponeso (431-404 a. C.), debido a que el estratega tenía como responsabilidad proponer una estrategia, que sería eventualmente debatida y aprobada (o rechazada) por la tribu, un estratega tenía que ser a la vez un claro pensador y un experto orador. En efecto, a lo largo de la historia de la guerra, los duelos intelectuales al interior de la 'tienda de campaña' y lejos del campo de batalla, a menudo han tenido efectos igual de profundos en el curso de la historia que muchos de los duelos entre grandes comandantes militares.

Existe evidencia de la ocurrencia de debates estratégicos desde el siglo $\mathrm{v}$ a. C. Por ejemplo, Temístocles tuvo que superar la preferencia de sus compañeros atenienses en confiar principalmente en la infantería pesada la seguridad y defensa de Atenas, convenciéndolos de destinar recursos para la construcción de una marina de guerra en contra de la recurrente amenaza de invasión por parte de los persas. Sus oponentes se resistieron a la idea señalando que los hoplitas y la formación militar cerrada de la falange habían derrotado cómodamente al Imperio persa en la batalla de Maratón. Sin embargo, en la visión de Temístocles, mientras los griegos no tuvieran el dominio en el mar, los persas podrían seguir intentando la conquista de Grecia, hasta un día alcanzarla. Esta línea de pensamiento se impuso finalmente y una importante flota marítima fue construida, esto constituyó para los griegos una gran victoria naval en Salamina y paralizó a la segunda fuerza expedicionaria persa que había invadido Grecia en el transcurso de una década; en últimas, Salamina aseguraría la salvación de Atenas, el futuro de la Grecia independiente e incluso el ascenso de Occidente.

\section{I.2 SUN TzU}

Un poco antes de que Tucídides (1986) escribiese su Historia de la Guerra del Peloponeso en Grecia (hacia el 400 a. C.), Sun Tzu (2012) ya había producido su tratado sobre estrategia militar en China (entre el 500 y el 600 a. C.), a pesar que este notable documento no influiría el pensamiento estratégico occidental hasta el siglo xviIr. En el Arte de la Guerra, la idea central del modelo de estrategia militar de Sun Tzu sería utilizar la astucia para hacer que el enemigo depositara las armas 
y se rindiera antes de haber comenzado a combatir. En otras palabras, para Sun Tzu, el mejor estratega militar sería aquel que ganase una guerra sin necesidad de combatirla (ecos de las estrategias de disuasión). Además, enfatizaría que una mano de obra, posición y tecnología superiores permitiría prevalecer sobre el adversario (ventaja competitiva y visión basada en los recursos).

Consideraba que era mucho más productivo atacar los puntos débiles del enemigo que atacar sus fortalezas. Atacar la debilidad sería aprovechar los recursos limitados del propio Estado, mientras que atacar la fortaleza sería desperdiciarlos (estrategia de aproximación indirecta). Para Sun Tzu (2012) era posible ganar de muchas maneras sin la necesidad de combatir; en su apreciación, las acciones sutiles, indirectas, menos notorias, tendrían menos probabilidades de provocar respuestas indeseadas por parte del enemigo. Por ende, cualquier acción exitosa que retrasase o no provocase una respuesta del ejército enemigo daría como resultado una victoria.

El pensamiento estratégico de Sun Tzu ha influenciado a teóricos de la estrategia en Oriente y Occidente hasta nuestros días, esto incluye a Mao Tsé-tung y Lidell Hart. Por ejemplo, ante las devastadoras consecuencias producto de la Primera Guerra Mundial, que impediría la obtención de objetivos estratégicos militares de los actores involucrados, el pensamiento de Sun Tzu influiría en la evolución del pensamiento estratégico occidental, a partir de los aportes de B. H. Lidell Hart. En efecto, Lidell Hart estuvo horrorizado por la destrucción física de esta 'Guerra de Segunda Generación', plagada de grandes ofensivas directas, que acabaron con una cantidad abrumadora de vidas humanas, y una falta de habilidad de las fuerzas militares para lograr éxitos terrestres tácticos decisivos (Álvarez et al., 2017).

Según Liddell Hart (1954), tratar de derrotar al enemigo empujando masas contra masas de manera insistente en el mismo plano de ofensivas directas tradicionales, que se repitieron con torpeza, fue producto de seguir la lógica de Clausewitz, ya que, al mostrar la batalla como única actividad de la guerra, el militar prusiano había privado a la estrategia de sus laureles, lo que reducía el arte de la guerra a mecanismos de exterminio e incitaba a los generales a buscar la batalla a la primera oportunidad, en vez de crear una oportunidad ventajosa. ${ }^{15}$ Liddell Hart estudiaría 25 siglos de guerras y concluiría que, en 30 conflictos mayores, que involucraban 280 campañas militares, en solo seis oportunidades un resultado decisivo había seguido un plan de aproximación estratégica directa a las fuerzas principales del

15 La metodología de Clausewitz, que distingue entre la "guerra teórica" o la "guerra absoluta" y la guerra en la realidad, ha llevado a muchos a identificarlo erróneamente como un apóstol de la "guerra total". De hecho, Clausewitz argumentaría que la guerra se podía luchar bien fuese por objetivos limitados o ilimitados, con medios parciales o totales. 
enemigo. En consecuencia, y con base las batallas históricas, consideraría que la estrategia de aproximación indirecta era por lejos, la más exitosa y económica de las estrategias de guerra (figura 2). Más aún, en casi todos esos casos de empleo exitoso de la aproximación indirecta, el bando victorioso había ganado una ventaja psicológica sobre el enemigo antes que tuviera lugar un encuentro físico. En consecuencia, Liddell Hart buscó una alternativa al conflicto en el ámbito físico y sus consecuentes resultantes de pérdida de vidas y propiedades, encontró respuesta en Sun Tzu, quien había dicho que

el concepto expresado por Cheng, normal [o directo] y Chi, extraordinario [o indirecto], tiene una importancia básica [...]. Las fuerzas normales [Cheng] fijan o distraen al enemigo; las fuerzas extraordinarias [Chi] actúan donde y cuando su empleo no ha sido anticipado. (Sun Tzu, 2012, p. 37)

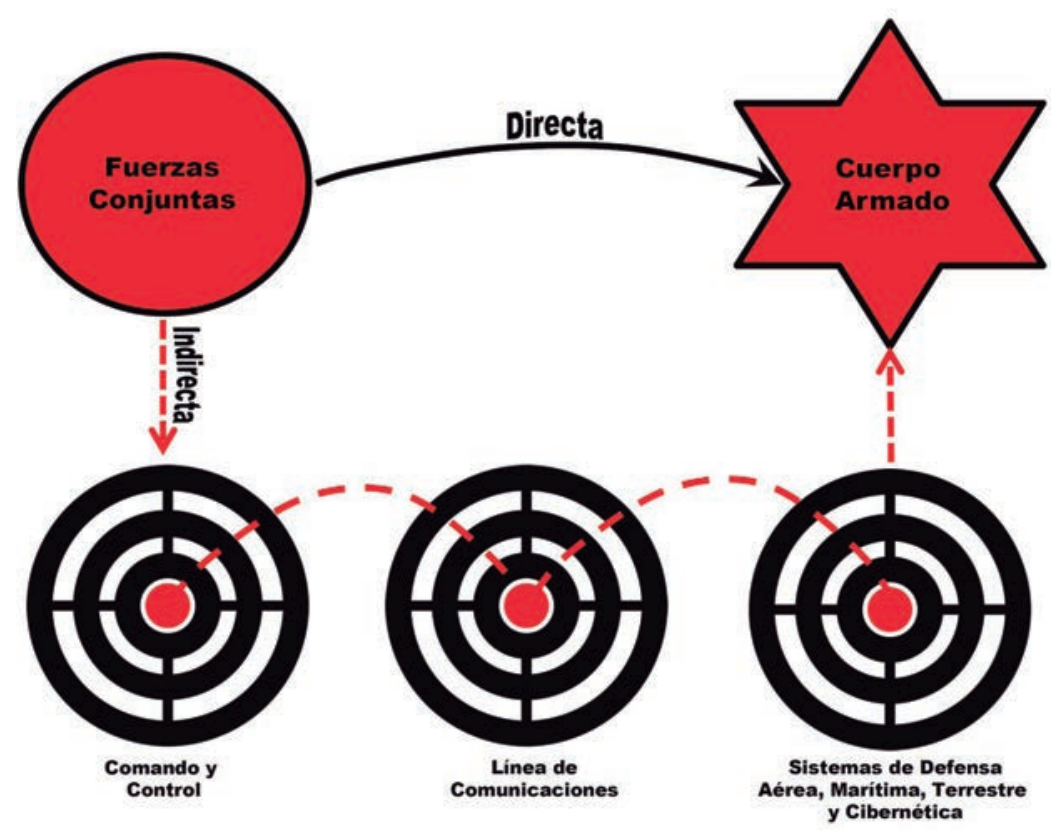

Figura 2. Aproximación indirecta versus aproximación directa.

Fuente: elaboración propia, a partir de Schnaubelt, Larson y Boyer (2014).

Por ende, Liddell Hart (1954) establecería que la más efectiva aproximación indirecta sería cuando, por efecto de un seńuelo, se indujera al enemigo a un movimiento en falso. Por ejemplo, Alejandro Magno prefirió enfrentar los riesgos que imponía la naturaleza, al cruzar desiertos, ríos y montañas, que por grandes que 
fueran, en todo caso, serían riesgos más aceptables que el de un ataque directo al enemigo; gracias a esto, sorprendería a sus enemigos lejos del frente de combate esperado por ellos. De igual manera, Aníbal y Napoleón cruzarían los Alpes, y San Martín y Simón Bolívar la cordillera de los Andes, sorprenderían así al enemigo, ya que el movimiento inicial de la aproximación indirecta sería psicológico, en busca de quebrar el ánimo del enemigo y su disposición a luchar.

Sun Tzu ofrecería una aproximación indirecta, que buscaba la victoria en el ámbito moral de la guerra, a través de la dislocación del enemigo y no de la destrucción física de la masa de las fuerzas del enemigo. Por lo tanto, el Arte de la Guerra sería el primer intento conocido por formular una base racional para el planeamiento y la conducción de operaciones militares. Haría hincapié en la importancia de luchar bajo las propias condiciones y no las del enemigo; es decir, examinaría formas alternativas de alcanzar la victoria en lugar de hacerlo por la fuerza bruta. ${ }^{16}$ Hoy en día, estos y otros métodos constituirían lo que se conoce como 'el poder suave' (diplomático, informativo, militar y económico), que se abordará con mayor detalle en el capítulo iv de este volumen.

A pesar del aporte de Sun Tzu al pensamiento estratégico desde el siglo v a. C., solo hasta finales del siglo XviII existiría en Occidente un claro concepto de los planes del general y su ejecución de maniobras en el periodo previo a la batalla. En efecto, el teniente coronel francés Paul Gideon Joly de Maizeroy, en su obra Théorie de la Guerre, ya identificaba en 1777 un segundo nivel en el arte de guerra, al que llamaba 'estrategia', y que dependía más de la razón que de las reglas. Para este militar,

hacer la guerra es una cuestión de reflexión, combinación de ideas, previsión, razonamiento en profundidad y uso de los medios disponibles [...] Para formular planes, la estrategia estudia la relación entre tiempo, posiciones, medios y diferentes intereses, y toma en cuenta cada factor [...], que es la provincia de la dialéctica, es decir, del razonamiento, que es la facultad más elevada de la mente. (Corvisier, 1994, p. 769)

\section{I.3 Antoine Henri de Jomini}

Según Gat (1989), la concepción moderna de la 'estrategia' llegaría a ser un producto del crecimiento de los ejércitos profesionales permanentes, por un lado, y de la corriente de la Ilustración, por el otro. Las guerras napoleónicas, con

16 Sun Tzu aconsejaba, en primera medida, atacar la estrategia del enemigo, luego sus alianzas, después su ejército y por último sus ciudades. 
ejércitos cada vez más numerosos, confirmarían la distinción entre táctica y estrategia, es decir, entre lo que sucedía en el campo de batalla y fuera de este. Antes de Napoleón, los estudios sobre la guerra se referían casi con exclusividad a la geometría del enfrentamiento táctico; por tanto, sería mérito del Barón Antoine Henri de Jomini, un oficial del Estado Mayor de la era napoleónica, elevar el análisis de lo táctico a los niveles operacionales y estratégicos, razón por la cual ha sido proclamado como el padre de la ciencia de la guerra. Antes de Jomini, en el siglo XVIII, muchos pensadores militares pusieron su atención en describir las formaciones de batalla y cómo las 'fuerzas' debían ser desplegadas en el campo de batalla. No obstante, Jomini (1977) puso su atención en entender cómo eran conducidas las operaciones, a partir de lo observado en las guerras napoleónicas. En Napoleón veía un hombre cuyo éxito atribuía a su entendimiento para emplear las fuerzas militares a gran escala, cosa que pudo hacer, según Jomini, porque tuvo la visión de planear una campaña militar en tiempo y espacio. En otras palabras, Jomini cambió la atención del siglo xviII sobre la táctica, hacia lo que él llamaría la "ciencia de la estrategia”.

Como un discípulo de la Ilustración y la 'edad de la razón', Jomini estaba entusiasmado con el enfoque científico para analizar los asuntos humanos y aplicar conscientemente el método científico (como él lo entendía), a sus estudios sobre la historia militar. Como resultado de estos estudios, descubriría lo que consideraba serían paradigmas comunes de comportamiento en las operaciones militares, que codificaría en axiomas y principios para instruir mejor a otros oficiales acerca de cómo organizar, planear y conducir la guerra 'moderna', los cuales tomarían posteriormente la forma de "principios de conducción", en lo que se conoce en la actualidad como "arte operacional". ${ }^{17}$

Según Jomini (1977), el 'arte de la guerra' estaba conformado por seis partes definidas: primero, el arte de gobernar en su relación con la guerra $;^{18}$ segundo, la estrategia o el arte de dirigir masas al teatro de la guerra (bien fuera para la defensa

17 Jomini expuso por primera vez conceptos de nivel operacional, tales como 'líneas de abastecimiento', 'punto estratégico', 'punto decisivo' y 'maniobra desde una posición central'.

18 En este sentido, Jomini establecía que los Estados tomaban la decisión de participar en la guerra para cumplir algunos de los siguientes objetivos o fines: para reclamar ciertos derechos o defenderlos; para proteger y mantener los grandes intereses del Estado (tales como el comercio, la manufactura o la agricultura); para conservar los Estados vecinos cuya existencia sería necesaria, ya fuese para la seguridad del gobierno o para el balance de poder; para cumplir con las obligaciones de las alianzas ofensivas y defensivas; para propagar teorías políticas o religiosas (con la intención de acabar con ellas o, por el contrario, para defenderlas); para incrementar la influencia y el poder del Estado por medio de la adquisición de nuevos territorios; para defender la independencia amenazada del Estado; para vengar el honor insultado; o como una mera manía o necesidad de conquistar a otros. 
o para la invasión); tercero, la gran táctica o el arte de apostar tropas sobre el campo de batalla de acuerdo con los accidentes del terreno, de llevarlos a acción y el arte de combatir en terreno (en contraposición a planearlo sobre un mapa); ${ }^{19}$ cuarto, la logística o el arte de mover los ejércitos; ${ }^{20}$ quinto, la ingeniería o el ataque y la defensa de fortificaciones; y sexto, las tácticas menores.

De acuerdo con Jomini (1977), la estrategia comprendería el arte de hacer la guerra sobre el mapa y abarcar el escenario de operaciones por completo; en consecuencia, la estrategia comprometía la selección del escenario de la guerra, la selección del punto objetivo (fuese ofensivo o defensivo), los frentes estratégicos, las líneas de defensa y los frentes de operaciones. En otras palabras, con la estrategia se decidiría dónde actuar, la logística llevaría las tropas a ese punto y la gran táctica decidiría la forma de ejecución y el empleo de las tropas. Por ende, al elevar el análisis de los niveles tácticos hacia los niveles operacionales y estratégicos, Jomini haría una gran contribución a la evolución del pensamiento estratégico militar. No obstante, al tratar de reducir la teoría de la guerra a una ciencia sistemática de elementos claramente clasificados y gobernados por principios universales inmutables, Jomini pudo haber confundido a generaciones de futuros estrategas sobre la verdadera naturaleza de la guerra (Arquilla y Nomura, 2015).

\section{I.4 Carl von Clausewitz}

Es sobre la consideración anterior que Carl von Clausewitz, soldado prusiano y filósofo de la guerra, establecería una aguda crítica a la propuesta jominiana. Al contrario de Jomini, para quien Napoleón había sido en realidad la culminación del pensamiento estratégico del siglo anterior, Clausewitz (1989) quiso reflejar en De la guerra, que lo que él había presenciado era algo totalmente nuevo. Curiosamente, el debate estratégico entre Jomini y Clausewitz reflejaba un debate cultural más grande entre los pensadores de la Ilustración (que creían que la ciencia, la estructura y el racionalismo podían resolver prácticamente todos los problemas), y los románticos (que reaccionaron y resistieron la idea de que el mundo podría ser dominado por la razón y creyeron, en cambio, que el profundo poder de la voluntad humana y la emoción permitirían prevalecer y superar todos los obstáculos).

19 La gran táctica relacionaba los siguientes objetos: la selección de posiciones y líneas defensivas de la batalla; la ofensiva en una batalla defensiva; las diferentes órdenes de batalla o las grandes maniobras adecuadas para el ataque a las líneas del enemigo; la colisión de dos ejércitos en marcha o batallas inesperadas. táctica.

20 La logística comprende los medios y los arreglos que hacen efectivos los planes de la estrategia y la 
Cuando Clausewitz desarrolló su teoría sobre la guerra, el sistema internacional experimentaba una serie de transformaciones que no escaparon a su análisis. En efecto, las revoluciones en las colonias de Norteamérica y en Francia daban inicio a las repúblicas liberales, un modelo político totalmente diferente al de los Estados absolutistas. Asimismo, la primera revolución industrial se había consolidado en Gran Bretaña y comenzaba a extenderse al resto de Europa; además, la corriente del Romanticismo, con su elogio de la 'pasión', sustituía al racionalismo imperante en el siglo anterior. Por ende, Clausewitz sería testigo de todos estos cambios e intentaría dejar por escrito su visión de cómo todos estos acontecimientos afectarían al fenómeno de la guerra.

De acuerdo con Smith (2005), Clausewitz abordaría el estudio de la guerra a partir de cuatro consideraciones distintas. Primero, la guerra era sobre matar y morir; es decir, Clausewitz no admitía la idea de que la guerra se pudiese librar sin el derramamiento de sangre. Segundo, la guerra era una competencia entre ejércitos, generales y Estados; en efecto, Clausewitz invocaba la metáfora de la lucha para describir la guerra como una competencia física y mental, donde cada una de las partes involucradas trataba de inmovilizar al adversario. Tercero, la guerra era un instrumento de política, es decir, una actividad que buscaba servir a los fines del Estado. Cuarto, la guerra era una actividad social; como alguien que había vivido la revolución francesa y había combatido en las guerras napoleónicas, Clausewitz era consciente del hecho de que las condiciones sociales moldeaban el carácter y la conducta de la guerra.

De la Guerra está dividida en 128 capítulos con sus correspondientes secciones, agrupados en ocho volúmenes. El primero de ellos, sobre la naturaleza de la guerra, define las características generales de la guerra en el mundo social y político e identifica los elementos que están siempre presentes en ella: peligro, esfuerzo físico y mental, factores psicológicos y aquellos impedimentos que dificultan las intenciones de cada una de las partes, que Clausewitz denominaba "fricciones". El segundo volumen, sobre la teoría de la guerra, subraya las posibilidades y limitaciones de las teorías. El tercer volumen, sobre la estrategia en general, incluye no solo capítulos sobre la fuerza, el tiempo y el espacio, sino también una detallada explicación sobre los elementos psicológicos. El cuarto volumen, sobre el combate, discute la actividad militar y la lucha que, por sus efectos materiales y psicológicos, abarca el objetivo general de la guerra. Los volúmenes quinto (acerca de las fuerzas armadas), sexto (sobre la defensa), y séptimo (dedicado a la ofensiva), constituirían a su vez, las tres partes más convencionales de la obra literaria (desde el punto de vista militar), e ilustran y amplían los argumentos de los primeros volúmenes. Por 
último, el octavo volumen, sobre los planes de guerra, vuelve a tratar los temas más importantes del primer volumen, explora las relaciones entre la "guerra absoluta" y la guerra en la realidad, analizando el carácter político de la guerra y la interacción entre la política y la estrategia.

Según Mahnken (2016), la obra de Clausewitz podría considerarse la piedra angular en el estudio de la teoría estratégica, ya que varios de los conceptos que Clausewitz presenta en De la Guerra son centrales para el estudio de la estrategia; estos incluirían la necesidad de comprender la naturaleza y el cálculo racional de una guerra, el centro de gravedad, la trinidad de la guerra, la diferencia entre guerras limitadas e ilimitadas, la fricción, entre otros. Con relación al primer concepto, Clausewitz (1989) argumenta que comprender la naturaleza de la guerra sería una precondición necesaria en el desarrollo de una efectiva estrategia. Por ello,

el primer acto de discernimiento, el mayor y el más decisivo que llevan a cabo un estadista y un jefe militar, es el de establecer correctamente la clase de guerra en la que están empeñados y no tomarla o convertirla en algo diferente de lo que dicte la naturaleza de las circunstancias. Este es, por lo tanto, el primero y el más amplio de todos los problemas estratégicos. (pp. 88-89)

Desde la perspectiva de Clausewitz, la naturaleza de la guerra es el resultado de la interacción de los objetivos estratégicos de ambas partes en conflicto, de sus sociedades, de sus gobiernos y de sus fuerzas militares, así como de las posturas de aliados y neutrales. Por ende, la estrategia sería más un arte que una ciencia; debido a que la naturaleza es el producto de la interacción entre distintos actores, cada guerra seria única y dinámica, ya que un cambio en cualquiera de sus elementos podría llegar a transformar la naturaleza del conflicto. ${ }^{21}$

En este orden de ideas, la diferente naturaleza de la dirección política con respecto a la militar quedaría muchas veces en evidencia cuando, por ejemplo, un militar profesional alcanza el poder político. En efecto, cuando el general Charles de Gaulle se convirtió en presidente de la v República, en 1959, se esperaba que hiciese un esfuerzo suplementario para aplastar la rebelión en Argelia. Sin embargo, tomó la decisión de abandonar el territorio, pese a que sobre el terreno la guerra estaba casi ganada para las tropas francesas; y pese a que la decisión provocó varios intentos de golpe de estado y de asesinato sobre su persona, De Gaulle comprendió

21 Para Sun Tzu (2012) habría siempre que adaptar nuevas tácticas y estrategias a cada nueva situación de conflicto, pues no porque una solución valiera ayer valdría siempre. Argumentaba que si se repetían las tácticas victoriosas del pasado, se corría el riesgo de encontrar un enemigo más aguerrido que habría pasado el tiempo estudiando la propia estrategia y cómo hacerle frente convenientemente. 
que, a largo plazo, Argelia era insostenible y Francia no debía agotarse en un conflicto interminable con un objetivo imposible.

De manera similar, al asumir la presidencia de Colombia, el 13 de junio de 1953, el general Gustavo Rojas Pinilla entendía que la naturaleza de la violencia interpartidista de la primera mitad del siglo xx en Colombia (que ya había dejado un saldo aproximado de 144.458 muertos), se circunscribía a grupos de campesinos sin mayor coordinación entre sí y sin objetivos concretos, lo que los alejaba de una guerra de guerrillas ideologizada. Por lo tanto, al comprender que el proceso de pacificación sería más fácil si lo trataba de manera directa, el general Rojas decretó una amnistía muy generosa para todos aquellos que se hubieran alzado en armas, iniciativa que recibió una respuesta positiva ya que la inmensa mayoría de guerrilleros liberales se desmovilizó y se acogió a la amnistía ofrecida.

Este tipo de razonamiento chocaría frontalmente con el pensamiento militar, que tiende a focalizarse en el problema inmediato de conseguir la victoria, resistiéndose a dar por terminado un conflicto en el que se han perdido muchas vidas y mucho prestigio. Pero, como Clausewitz argumentaría, el rasgo principal de los militares sería la voluntad para doblegar al enemigo, y no el cálculo racional que decide cuándo vale la pena luchar y cuando no, que sería terreno de lo político. El reconocimiento de Clausewitz del carácter político de la guerra reforzaría la idea de que la esta no es un acto autónomo o aislado; la derrota del poder bélico del enemigo, y de su voluntad para utilizarlo, no sería el fin en sí mismo, sino un medio para lograr los objetivos políticos. Por ende, la violencia debería ser la expresión del propósito político, razón por la cual, los líderes políticos deberían controlar y conducir la guerra.

Para Clausewitz (1989), la estrategia debería ser un proceso racional, ya que "nadie en sus sentidos debería comenzar una guerra, sin antes tener claro en su mente lo que intenta lograr con esa guerra y cómo llevarla a cabo" (p. 579). En este sentido, una estrategia exitosa se basaría en la identificación clara de los objetivos políticos, la evaluación de la ventaja comparativa relativa del enemigo, el cálculo cuidadoso de los costos y los beneficios, y el examen de los riesgos y las recompensas de las estrategias alternativas. Sin embargo, Clausewitz reconocía que, en ocasiones, los Estados iban a la guerra sin objetivos claros o una estrategia para alcanzarlos; algunas veces, los estadistas y soldados se comprometían en guerras por objetivos mal definidos, o sin una política coherente que hacía que la estrategia se volviese ineficaz, porque carecía de dirección.

Para Clausewitz, "la guerra era un fenómeno temporal en el que el futuro, el presente y el pasado chocaban como placas tectónicas" (Kornberger, 2013, p. 1062). 
Es decir, la guerra seguía una lógica paradójicamente temporal, en la que la línea del tiempo se doblaba y el futuro tenía el poder de moldear el presente; en consecuencia, la guerra estaría influenciada por expectativas de lo que podría suceder después de que terminara, lo que a su vez influiría en el curso de los acontecimientos (Herberg-Rothe, 2014). Comprender la naturaleza de la guerra a enfrentar permitiría una mejor apreciación acerca de cuál sería la propia ventaja comparativa, esto, a su vez, formaría la base de una sólida estrategia. La clave para hacerlo, en opinión de Clausewitz, sería entender el centro de gravedad del enemigo.

Desde el punto de vista militar, el origen del concepto de centro de gravedad se le atribuye a Clausewitz. Pareciera que su idea de centro de gravedad se consolidaría luego de asistir, en la Allgemeine Kriegsschule (Escuela general de guerra prusiana), a una serie de conferencias dictadas por parte del físico alemán Paul Herman. En física, el centro de gravedad representaría el punto donde las fuerzas de la gravedad convergen dentro de un objeto; también sería el punto en el cual, al aplicar una fuerza, el objeto se movería eficazmente. Por lo tanto, si se llegase a golpear el centro de gravedad con bastante fuerza, sería posible que el objeto perdiese su equilibrio y cayese.

Uno debe tener en cuenta las características dominantes de ambos beligerantes. De estas características se desarrolla un cierto centro de gravedad, el centro de todo poder y movimiento del que todo depende. Ese es el punto contra el cual deben dirigirse todas nuestras energías. (Clausewitz, 1989, pp. 595-596)

En este orden de ideas, el centro de gravedad se enfocaría en lograr un efecto específico, es decir, el colapso del enemigo. Por lo tanto, se trataría de un enfoque basado en los efectos, en lugar de uno basado en las capacidades. En concreto, según Clausewitz (1989), se podrían llegar a identificar cinco centros de gravedad distintos y con diferente importancia: 1) la destrucción del ejército enemigo (cuando este ejército sea realmente una fuerza consistente); 2) conquista de la capital del enemigo (cuando no es solo el centro de los grandes poderes del Estado, sino también, la residencia de las asambleas políticas); 3) ataque a los aliados del enemigo; 4) el líder del enemigo y 5) la opinión pública del enemigo.

En general, el concepto de centro de gravedad ha tenido una influencia importante en el desarrollo de las estrategias militares alrededor del mundo y, si bien se ha alejado de la idea original de Clausewitz, ha evolucionado desde el concepto "punto decisivo” de Jomini ${ }^{22}$ (características geográficas vitales, límites entre grupos de ejér-

22 Jomini definió un punto decisivo como cualquier cosa "cuyo ataque o captura pondría en peligro o debilitaría seriamente al enemigo" (Shy, 1986, pp. 152-154). 
cito y líneas de comunicación), a una "fuente de fortaleza" clave del adversario. En la doctrina conjunta para el planeamiento de campańa de los Estados Unidos, se define 'centro de gravedad' como aquellos "aspectos de la capacidad global del adversario que, teóricamente, si son atacados y neutralizados o destruidos, conducirán inevitablemente a la derrota del adversario o forzarán al oponente a abandonar sus objetivos o a cambiar de conducta" (Joint Chiefs of Staff, 2002, p. 6). Por su redacción, esta definición podría ser empleada para analizar los centros de gravedad en todos los niveles de la guerra (figuras 3 y 4), si se toma en consideración que Clausewitz no distinguiría entre centros de gravedad tácticos, operativos o estratégicos; para Clausewitz, el centro de gravedad estaría definido por todo el sistema (o estructura) del enemigo, y no por un nivel de la guerra (Echevarría, 2002).

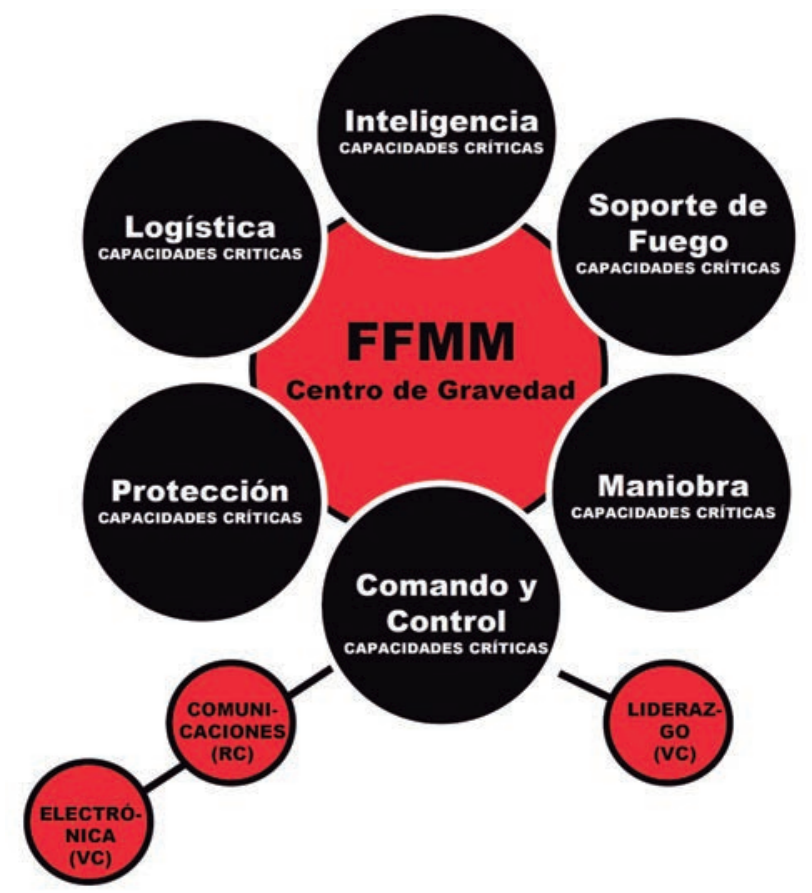

Figura 3. Análisis del centro de gravedad táctico y operacional. ${ }^{23}$

Fuente: elaboración propia, a partir de Schnaubelt, Larson y Boyer (2014).

23 Las capacidades críticas (cc) serían las principales habilidades a identificar en un centro de gravedad, cuya existencia es esencial para la supervivencia del adversario. Los requisitos críticos (CR) serían las condiciones, recursos y medios esenciales que el centro de gravedad requiere para llevar a cabo la capacidad crítica; estos se usan o consumen para llevar a cabo acciones, lo que permite una capacidad crítica para funcionar por completo. Por su parte, las vulnerabilidades críticas (cv), serían los requisitos críticos o componentes de estos que son deficientes o vulnerables de neutralización, interdicción o ataque de una manera que logre resultados decisivos (Schnaubelt, Larson y Boyer, 2014). 


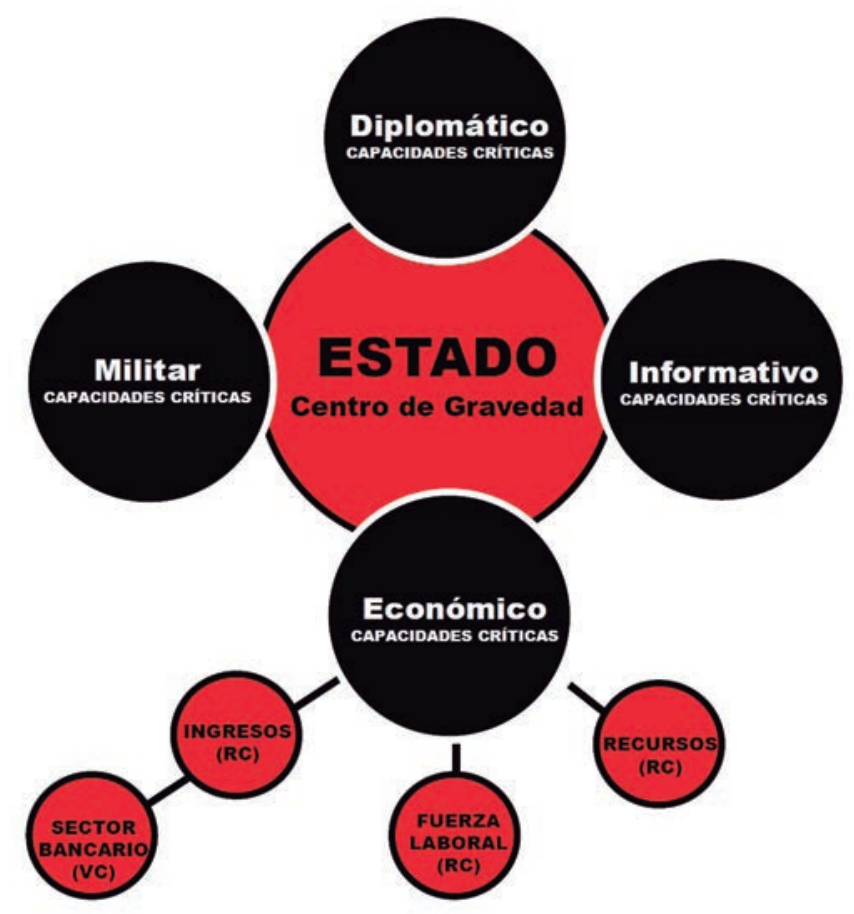

Figura 4. Análisis del centro de gravedad estratégico.

Fuente: elaboración propia, a partir de Schnaubelt; Larson y Boyer (2014).

Para la doctrina de defensa británica, un centro de gravedad sería "aquella característica, capacidad o ubicación desde la cual una fuerza militar, nación o alianza, obtiene su libertad de acción, su fuerza física o su voluntad de lucha" (Defense Council, 2004, p. 112). En consecuencia, la doctrina británica establece que el éxito en el conflicto podría ser logrado al identificar, controlar o destruir los centros de gravedad del enemigo; dichos centros de gravedad podrían llegar a ser: 1) la masa del ejército enemigo; 2) un área geográfica en particular; 3) un recurso crítico; 4) el mando o los principales líderes y 5) la estructura de mando y control del enemigo o su voluntad de lucha en el ámbito nacional.

Cabe destacar la importancia en el hecho de la incorporación de la psicología como un elemento fundamental de la teoría de Clausewitz. Desde la antigüedad los pensadores habían resaltado la importancia de las emociones en la guerra, pero se limitaron a establecer una lista de aquellos que fuesen deseables e indeseables a experimentar por parte de los soldados. De la Guerra estableció que la psicología del soldado, la de su comandante y la de la sociedad a la que servirían, eran una parte esencial de la teoría sobre la guerra, por lo que Clausewitz dio el paso decisivo 
al situar al análisis de las fuerzas psicológicas en el mismo centro del estilo de la guerra. En este orden de ideas, para las Fuerzas Militares de Colombia, un centro de gravedad sería una fuente de fortaleza física o moral (psicológica), cuya neutralización, degradación, dislocación o destrucción tendría un impacto decisivo en el logro de los objetivos ofensivos o defensivos establecidos (FFMM, 2005).

Con relación a guerras limitadas e ilimitadas, Clausewitz establecería que las guerras se pueden luchar por una amplia gama de objetivos, desde la búsqueda de tierras y recursos, hasta la destrucción total del enemigo. En este sentido, Clausewitz haría una distinción entre guerras peleadas por objetivos limitados y aquellas luchadas por objetivos ilimitados, así

la guerra puede ser de dos clases, en el sentido de que el objetivo es derrocar al enemigo, bien sea dejándolo políticamente impotente o militarmente indefenso, forzándolo a firmar la paz que queramos, o simplemente ocupando algunos de sus distritos fronterizos para que podemos anexarlos o usarlos en las negociaciones de paz. (Clausewitz, 1989, p. 69)

La distinción entre guerra limitada y guerra ilimitada afectaría la forma como se combaten las guerras y como estas terminarían. Debido a que las guerras limitadas, como las de Corea y Vietnam, se llevarían a cabo sin emplear armas nucleares, muchos suponen que eso es lo que significa una guerra limitada, es decir, una guerra que estaría limitada al empleo de armas convencionales. No obstante, esa no sería una definición correcta ya que las guerras limitadas vendrían definidas por la naturaleza 'limitada' de sus objetivos, es decir, en guerras con objetivos 'limitados' los militares y políticos deberían traducir en influencia política sobre el adversario los éxitos operacionales obtenidos en el campo de batalla.

En otras palabras, en las guerras limitadas las operaciones militares serían consideradas un mecanismo altamente politizado de uso de la coerción y la disuasión en el discurrir de la crisis y la guerra, diseñado para producir un acuerdo negociado y no una victoria militar total. La estrategia estaría diseñada para erosionar la voluntad de luchar del adversario, más que denegarle los medios (destrucción de sus capacidades militares), para hacerlo. En consecuencia, dichas guerras terminarían a través de negociaciones o acuerdos de paz entre las partes en conflicto y no como resultado de la destrucción total de las capacidades militares del adversario. Usualmente, el final de las guerras limitadas podría provocar insatisfacción por parte de una de las partes, debido al sacrificio de recursos y un compromiso militar prolongado, que no se perciben honradas en la concesión de privilegios en los acuerdos de paz a los adversarios, como ha sido el reciente caso colombiano. 
En contraste, se librarían guerras por objetivos 'ilimitados' para derrocar al régimen enemigo o lograr su rendición incondicional, a través del aniquilamiento militar de este, razón por la cual este tipo de guerras terminarían en un acuerdo de paz que se impone y no se negocia. Además, las secuelas de una guerra por objetivos ilimitados conducirían a un compromiso prolongado de otro tipo, ya que los vencedores se verían obligados a esfuerzos para la reconstrucción del Estado, como le ocurriría a Estados Unidos al finalizar la Segunda Guerra Mundial con Alemania occidental y Japón.

Con respecto a la fricción, Clausewitz consideraría que las dificultades inherentes de la batalla creaban una "fricción" y "niebla de guerra" en el conocimiento, lo que impediría cualquier intento de adherirse a principios formales, como aquellos establecidos por Jomini. Según Clausewitz (1989), la "niebla de la guerra" era la incertidumbre en la conciencia situacional experimentada por los participantes en las operaciones militares, con respecto a la propia capacidad, la capacidad del adversario y la intención del adversario. ${ }^{24}$ Por su parte, la "fricción" se refería a las incertidumbres, errores, accidentes, dificultades técnicas, así como los imprevistos y los efectos que estos factores tenían en las decisiones, en la moral y en las acciones; era una combinación del azar, las dificultades inherentes a gestionar una gran organización en situaciones extremas, la tendencia al error de personas sometidas a un enorme estrés, la meteorología y las dificultades del terreno y, sobre todo, la acción del enemigo, una entidad inteligente y agresiva que reaccionaba ante cualquiera de las acciones que se emprendiesen. La fricción impedía que un jefe militar pudiera disponer de una receta infalible para el éxito, lo que obligaría que sus decisiones, aunque apoyadas por un planeamiento científico, significasen siempre la asunción de un riesgo y un ejercicio de responsabilidad, iniciativa e intuición. La fricción, como señalaría Clausewitz, era la fuerza que hacía difícil lo aparentemente fácil.

Es decir, la fricción hacía imposible la aplicación de un método totalmente científico a la resolución de las operaciones militares. Para Clausewitz (1989), la guerra se componía de diferentes elementos, algunos cuantitativos (cantidad de tropas o armas) y otros cualitativos (moral y coraje). Las circunstancias como el terreno y el clima, pero también la suerte y la coincidencia, jugaban un papel importante en el campo de batalla; debido a la interacción compleja de las fuerzas cualitativas y cuantitativas, y su naturaleza recíproca, el resultado de una batalla o una guerra desafiaba la planificación y la predicción. En lugar de ello, Clausewitz

24 Para reducir la "niebla de la guerra", Clausewitz consideraba que la información (conocimiento del enemigo y su territorio) era esencial para asegurar la victoria. 
argumentaba que solo "la genialidad" podría superar los retos psicológicos y estratégicos de la guerra. Desde esta perspectiva, pareciera que solo las personas con los más altos poderes de razonamiento podían encontrar el camino a la victoria en la guerra.

Con referencia a la trinidad, Clausewitz (1989) consideraba que la guerra real se componía de tres elementos: la violencia, el odio y la enemistad; el juego de la incertidumbre, el azar y la probabilidad; y el objetivo político y sus efectos. Con base en lo anterior, Clausewitz establecía que cada uno de estos tres elementos generalmente correspondía (aunque no siempre), a uno de tres grupos en la sociedad: las personas, los militares y el gobierno. En su conjunto, el primer elemento (pasión) estaría usualmente asociado con las personas, cuyas animosidades impulsarían a los Estados a luchar; el segundo elemento (incertidumbre, el azar y la probabilidad), harían parte del reino de los militares y del coraje, determinación y talento de los comandantes; y el tercer elemento (razón), sería un tema particular del gobierno, que determinaría los objetivos políticos de la guerra y los medios para llevarla a cabo. Clausewitz (1989) argumentaría que, según las circunstancias de la guerra, las relaciones y la intensidad relativa entre estos tres elementos constitutivos podrían llegar a cambiar:

Estas tres tendencias, que se ponen de manifiesto al igual que lo hacen muchas diferentes legislaciones, se asientan profundamente en la naturaleza de la cuestión y, al mismo tiempo, varían en magnitud. Una teoría que rehuyera tomar en cuenta cualquiera de ellas o fijara una relación arbitraria entre ellas incurriría en tal contradicción con la realidad que por este solo hecho debería ser considerada como nula. El problema consiste, pues, en mantener a la teoría en equilibrio entre estas tres tendencias, como si fueran éstas tres polos de atracción. (p. 69)

Con la idea de la "trinidad" (figura 5), Clausewitz establecía que la guerra era, además de una actividad militar, un fenómeno político y social. Por ende, a un conflicto armado deberían contribuir todos los elementos de una sociedad, que Clausewitz identificaba como tres (Stone, 2007): primero, los dirigentes políticos que aportan la racionalidad en la dirección del conflicto; segundo, los militares que ejercen la voluntad necesaria para imponerse al adversario; y tercero, la población que proporciona el apoyo emotivo y pasional que ayuda a realizar el esfuerzo supremo propio de una guerra. ${ }^{25}$

25 Según Liddell Hart (2008), esta idea amplificada hasta la irracionalidad llevaría a Europa al concepto de guerra total y a su dramática aplicación en ambas guerras mundiales. 


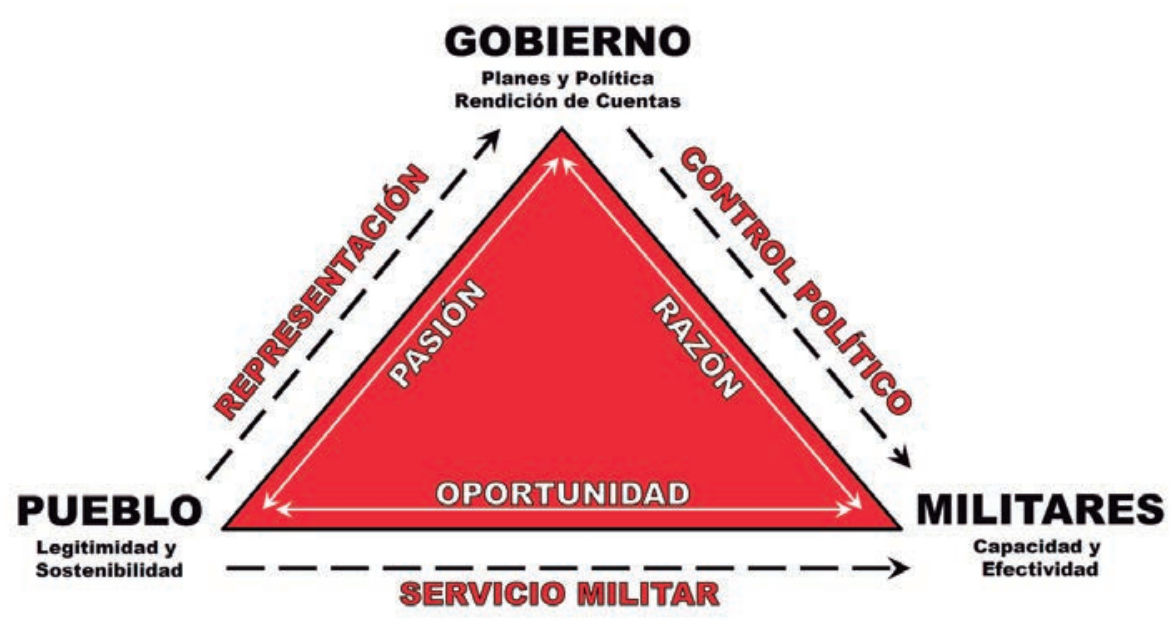

Figura 5. Trinidad de la guerra.

Fuente: elaboración propia con base en Clausewitz (1989).

Los sucesos de las guerras napoleónicas presentarían un creciente reconocimiento de la complejidad de la estrategia, resumida en la advertencia clausewitziana de que no podía existir una evaluación puramente militar de un gran problema estratégico, así como de un esquema puramente militar para resolverlo. Si bien en el nivel táctico los medios eran las fuerzas de combate entrenadas para alcanzar la victoria militar, no obstante, para lo estratégico, las victorias militares no tendrían sentido a menos que fuesen el medio para obtener un fin político, es decir, la paz (Clausewitz, 1989). Por lo tanto, la estrategia sería la vinculación (verbindung) de enfrentamientos separados de batalla en un único todo, para el objetivo final de la guerra, que tan solo el nivel político podría llegar a determinar. Es decir, para llevar a una guerra o cualquiera de sus campañas a un cierre exitoso, se requeriría un conocimiento completo de la estrategia nacional, es decir, aquel nivel en donde la estrategia y la política se unirían. Para Clausewitz, este contínuum vertical (figura 6) sería mejor ejemplificado por Federico el Grande, quien encarnaba tanto la política como la estrategia y cuyas conquistas de Silesia (1741), se considerarían el ejemplo clásico del arte estratégico, al demostrar un elemento de fuerza contenida, listo para ajustarse al cambio más pequeño en la situación política.

Con la descripción aparentemente simple del contínuum vertical de la guerra, Clausewitz (1989) prepararía el escenario para un cambio paradigmático en la estrategia con respecto a la relación entre medios y fines. Ahora la estrategia sería más compleja y operaría tanto en el nivel militar como el político, con la totalidad 

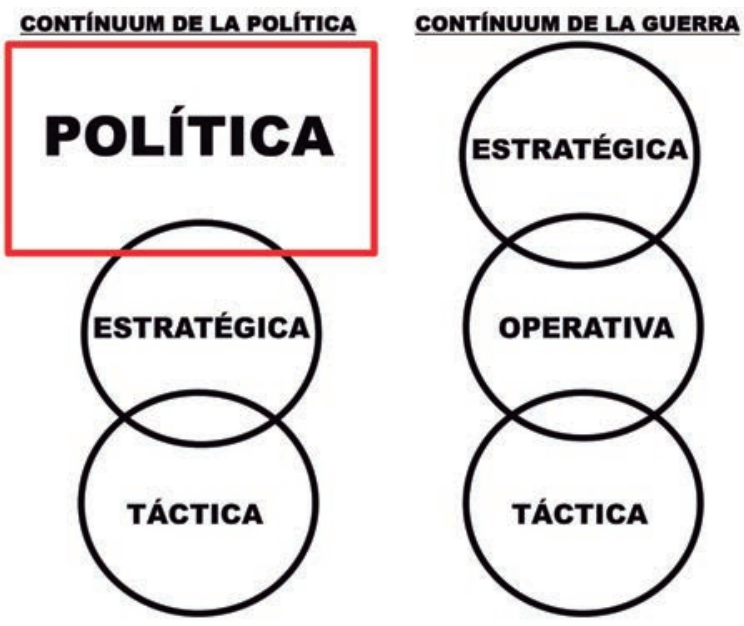

Figura 6. Contínuum de la política y de la guerra.

Fuente: elaboración propia

de fines, medios y modos en los niveles inferiores, interconectados con la aplicación de la política a nivel nacional de esos mismos elementos estratégicos. Esta conexión sería la esencia de la descripción de la guerra por parte de Clausewitz, como la continuación de la política (verkehr) con la adición de otros medios.

\subsection{Ecuación de la estrategia}

En 1981, el General Maxwell D. Taylor caracterizaría la estrategia en tres elementos: "objetivos", "formas" y "medios" (Lykke, 2001). Estos elementos serían deducidos a partir de la definición de "estrategia" aprobada por el Estado Mayor Conjunto de los Estados Unidos, según la cual la estrategia militar sería "el arte y la ciencia del empleo de las fuerzas armadas de una nación para asegurar los objetivos políticos nacionales mediante la aplicación o amenaza del uso de la fuerza" (Lykke, 1989, p. 2). A partir de lo anterior, Lykke (1989) propondría una aproximación conceptual de estrategia que pudiera ser empleada para cualquier elemento del poder nacional (no solo militar), llegando a la conclusión que estos elementos tenían un efecto acumulativo; por ende, el concepto de "estrategia" según Lykke (1989) se expresaría de la siguiente manera (ecuación 1):

\section{Estrategia $=$ Fines + Modos + Medios}

Ecuación 1. Modelo Estratégico según Lykke

Fuente: elaboración propia a partir de Lykke (1989). 
Posteriormente, Sánchez (2013) incluiría elementos adicionales a la ecuación de la estrategia, como los "riesgos", la "estrategia del adversario" y el "entorno", todos ellos con efectos igualmente acumulativos dentro de la estrategia (ecuación 2).

\section{$E=F+M e+M o+R+E A+E n$ \\ Estrategia $=$ Fines + Medios + Modos + Riesgo + Estrategia del Adversario + Entorno}

Ecuación 2. Ecuación Estratégica según Sánchez

Fuente: elaboración propia a partir de Sánchez (2013).

No sería posible afirmar que Sánchez haya usado como base para su propuesta de ecuación estratégica, el modelo de Lykke (1989); sin embargo, un simple análisis matemático permitiría identificar que en ambas propuestas, cada una de las variables que compondrían la ecuación serían consideradas como variables independientes unas de otras, lo cual no necesariamente estaría alineado con el proceso en la práctica. En consecuencia, para comprobar la consistencia de estas ecuaciones, sería necesario comprender como cada autor definiría cada una de estas variables.

Para comenzar, se podría partir del análisis de las tres variables comunes en las dos ecuaciones: "fines", "modos" y "medios". En el caso de los "fines", los dos autores concordarían en que estos hacen referencia a los objetivos orientados por la política, tal y como habría sido expresado por Clausewitz (1989) y Lidell Hart (1954). Es decir, los "objetivos" tendrían implícita la voluntad política. En cuanto al "modo", ambos utilizarían el término "concepto estratégico" para explicarlo, describiéndolo como un curso de acción escogido, el cual estaría siempre en relación con los "objetivos" y los "medios" disponibles. Finalmente, para los “medios", se apelaría a las capacidades y recursos disponibles para desarrollar las estrategias. De acuerdo con esto, se podría llegar a afirmar que la preocupación de los estrategas debería ser la identificación de "modos" para el empleo de "medios" que permitan alcanzar los "objetivos" en el nivel político. Es decir, el éxito de los "objetivos" estribaría tanto de los "medios" como de los "modos", lo cual pondría al descubierto que los "objetivos" serían una variable dependiente de las otras dos (medios y modos), y no necesariamente una suma. Es decir, que en términos matemáticos, los "objetivos" o "fines" serían una función de los "medios" y los "modos" (ecuación 3). 


\section{$F=f(M o, M e)$ \\ Fines $=f($ Modos, Medios $)$}

Ecuación 3. Los Fines en función de Medios y Modos

Fuente: elaboración propia

El planeamiento estratégico sería un proceso iterativo. Esto significaría que, aunque en el orden de precedencia del proceso de planeamiento, los "objetivos" se plantearían antes que los "medios" y los "modos", ya que estos determinarían, en últimas, si los "objetivos" serían alcanzables, o requerirían ser replanteados de manera que la implementación de la estrategia, no solo sea posible, sino que también sea eficaz. Visto de otro modo, alcanzar un "objetivo" propuesto dependería de los recursos y conceptos operacionales disponibles. En este orden de ideas, no todos los "fines" compartirían los mismos "medios" y/o "modos". Cada objetivo en sí mismo requeriría la utilización de recursos que podrían ser distintos tanto en su esencia como en su modo de empleo; por ello sería importante dar un valor único a cada "objetivo", de tal manera que la ecuación estratégica, hasta donde fue propuesta por Lykke y Sánchez, podría ser replanteada en una nueva ecuación (ecuación 4), en donde el subíndice $i$ representaría los "modos" y "medios" necesarios para cada "objetivo" $i$ que se llegase a identificar para alcanzar la estrategia.

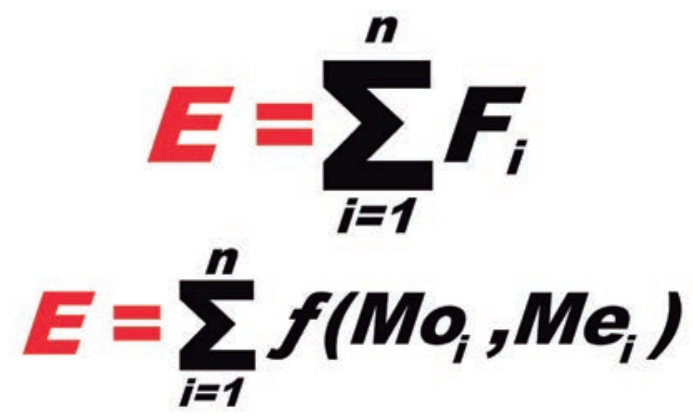

Ecuación 4. Primera Aproximación a una Nueva Ecuación Estratégica Fuente: elaboración propia

Con relación a las variables de los "riesgos", la "estrategia del adversario" y el "entorno" propuestas por Sánchez (2013), los "riesgos" jugarían un papel fundamental en el resultado de la estrategia, y estos podrían tener efectos tanto a favor (positivos) como en contra (negativos), por lo que deberían ser considerados siempre 
por los estrategas. Si bien Lykke (1989) no consideraría en su ecuación el "riesgo", no significaría que lo desconozca; para Lykke (1989) el "riesgo" se presentaría en la forma de un desbalance entre "medios" y "modos" para alcanzar los "objetivos", y que estos a su vez deberían ser necesarios y suficientes para evitar el desperdicio de "medios" y "modos". Esta visión podría ser limitada desde la perspectiva de Sánchez (2013), quien consideraría los riesgos en todo el contexto del entorno estratégico, pero que, como se explicaría, no sería del todo acertado. El "riesgo" sería inherente a cualquier actividad del ser humano, sobre todo en la guerra; por tal razón, sería probable que Lykke (1989) no los hubiese incluido como una variable más de su ecuación, puesto que su tratamiento haría parte de ese proceso iterativo que conllevaría la definición de "objetivos", "medios" y "modos". Si los "riesgos" serían una variable independiente, desde el punto de vista de Sánchez (2013), se podría hablar entonces de los "riesgos" residuales, aquellos que serían desconocidos, inciertos y que no podrían ser contemplados en el proceso de planeamiento estratégico, o que aparecerían de forma inesperada, a pesar de los esfuerzos de los estrategas por reducir su probabilidad de ocurrencia. Por otro lado, la "estrategia del adversario" sería una variable a considerar cuando se pondría en marcha la estrategia propia, considerando los posibles "fines", "medios" y "modos" que el adversario emplearía, permitiendo a su vez la adaptación de los propios. Finalmente, el "entorno" haría referencia al escenario en el cual se desarrollaría la estrategia, evaluando aspectos de todos los elementos del poder nacional; al igual que los "riesgos", estos podrían potenciar u obstaculizar la estrategia.

Resultaría importante resaltar que Sánchez (2013) reconocería los efectos de cada una de estas variables; sin embargo, estarían incorrectamente expresadas de forma matemática, al considerar su efecto acumulativo, y no como se ha evidenciado, a partir del análisis de sus definiciones, que estos efectos podrían ser activadores o limitadores. En el caso particular de los "riesgos" y el "entorno", como se ha visto, podría hablarse de una relación de dependencia de la variable "Estrategia", como sucede entre "objetivos", "modos" y "medios". Las implicaciones de estas variables estarían orientadas al valor final o, en otras palabras, al resultado de la misma.

Todas estas variables a su vez serían dependientes del "tiempo"; Holcomb (2004) lo expresaría en términos de la dinámica en el tiempo y circunstancia. Los "objetivos", "medios", "modos", "riesgos" y "entorno", variarían en el "tiempo" de acuerdo con las acciones propias y del adversario. Por ejemplo, la materialización de "riegos" residuales podría requerir de un ajuste en variables como los "medios", los "modos", un cambio de "entorno" o incluso a la reformulación de un "objetivo". 
Por ende, una destreza importante del estratega sería reconocer cuando cambiarían las variables en el tiempo, realizando los ajustes necesarios en ellas.

$$
\begin{aligned}
& E(t)=\left(\sum_{i=1}^{n} F(t), R(t), E n(t)\right) \\
& E(t)=\left(\sum_{t=1}^{n} f(\operatorname{Mo}(t), M e(t)), R(t), E n(t)\right)
\end{aligned}
$$

Ecuación 5. Ecuación Estratégica según Álvarez, Corredor \& Vanegas

Fuente: elaboración propia

La ecuación 5 sería una función vectorial, transformando en un vector las ecuaciones planteadas por Lykke (1989) y Sánchez (2013); el vector "estrategia" sería una variable en el "tiempo", debido a que como se expuso anteriormente, sus componentes serían también funciones dependientes del "tiempo". Antes de continuar el análisis de la ecuación, sería imprescindible analizar la relación entre la "estrategia" y "estado final deseado". Yarger (2006) indicaría que la "estrategia" proveería la dirección proactiva para la aplicación del poder coercitivo o persuasivo hacia un "estado final deseado", es decir, un conjunto de condiciones necesarias para dar por terminado un conflicto, y que estarían representados en los intereses de un Estado (o como se le denominaría en el ámbito corporativo, la visión); autores como Collins y Rukstad (2008) y Porter (2006) coincidirían en describir la "estrategia" como el "medio" para alcanzar la "visión", empleando "ventajas competitivas".

En el ámbito de los Estados, podría afirmarse que la Gran Estrategia sería igual a la "visión" corporativa o el "estado final deseado", y las "estrategias" particulares en cada ámbito del poder nacional, serían la estrategia empresarial. Ahora bien, la "estrategia del adversario" sería una fuerza que actúa en dirección contraria a la propia, para impedir que se alcance el "estado final deseado". Bien lo decía Baufre (1965), al definir la guerra como el arte de la dialéctica de dos voluntades opuestas, empleando la fuerza para resolver su disputa; estas voluntades serían efectivamente las estrategias propias y las del enemigo. En términos matemáticos, se podría argumentar que las estrategias, tanto la propia como la del adversario, serían dos vectores de cuya sustracción resultaría uno, denominado "estado final deseado". Por lo tanto, el planteamiento de la ecuación del estado final deseado 
sería la siguiente, en donde Ea sería "estrategia del adversario", Ef sería "estrategia final deseado" y Ep sería "estrategia propia” (ecuación 6):

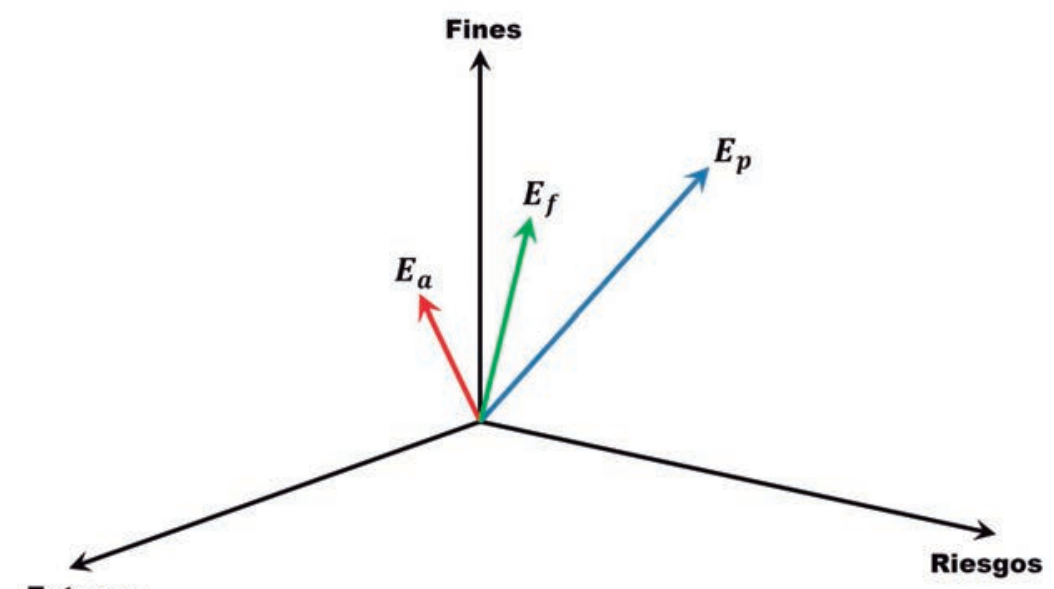

Entorno

Ecuación 6. Los Vectores de la Estrategia según Álvarez, Corredor y Vanegas Fuente: elaboración propia

\subsection{Niveles de la estrategia}

Dentro de las fuerzas militares existiría una jerarquía de términos que definen y delinean actividades específicas relacionadas con tácticas y estrategias, cada una de las cuales se refiere a un curso de acción y a una responsabilidad en particular; comenzarían en el nivel más bajo con la 'táctica', hacia el nivel más alto con la 'gran estrategia'. Los niveles de la estrategia de un Estado guardarían relación con los niveles de la guerra; de acuerdo al Manual de Doctrina mfe 1-01 de las Fuerzas Militares de Colombia, los niveles de la guerra serían un marco que permitiría definir y clarificar la relación entre los objetivos nacionales, el enfoque operacional y las tareas tácticas (Centro de Doctrina del Ejército, 2016). En consecuencia, los tres niveles de la guerra ${ }^{26}$ serían: estratégico, operacional y táctico.

De acuerdo al Centro de Doctrina del Ejército de Colombia (2016), el propósito de los niveles de la guerra sería enfocar a los comandantes en uno de tres amplios roles, correlacionándolos con niveles específicos de responsabilidad. Es decir, en

26 Según el Centro de Doctrina del Ejército (2016), "los niveles de la guerra no deben confundirse con los efectos que también pueden ser estratégicos, operacionales o tácticos y que pueden ser generados por cualquier escalón o incluso individuos" (p. 46). 
responsabilidades relacionadas con: 1) la creación de la estrategia; 2) la sincronización y secuencia de las batallas y combates; y 3) la realización de tareas tácticas.

Por consiguiente, frente a los niveles de la estrategia, la táctica describiría cómo pequeñas unidades militares (pelotones, compañías, barcos y escuadrones), deberían ser empleadas en un área de operaciones; ${ }^{27}$ las tácticas serían el empleo y la disposición ordenada de las unidades en relación con otras. A cargo de este nivel de la estrategia se encontrarían los comandantes de un unidades tácticas (batallones) y los comandantes de unidades operativas menores (brigadas), quienes, basados en un plan de campaña y un plan de operaciones, precisarían a través de una orden de operaciones ${ }^{28}$ aquellas acciones militares que deben llevarse a cabo por parte de los miembros de una unidad táctica en el área de operaciones. Este nivel de la estrategia guarda correspondencia con el nivel táctico de la guerra. De acuerdo al Centro de Doctrina del Ejército de Colombia (2016),

El nivel táctico hace referencia a la conducción de las acciones, batallas, combates y otras tareas tácticas para lograr los objetivos militares asignados a unidades tácticas o fuerzas de tarea. Cuando se llevan a cabo todas las tareas asignadas a unidades tácticas, se deben lograr resultados operacionalmente significativos. El nivel táctico de la guerra se dirige principalmente en la doctrina de fuerza. (pp. 44-45)

En un escalón superior (figura 7), la Estrategia Militar Operativa (emo) y el "arte operacional" 29 se referirían al movimiento de las unidades militares más grandes, incluidas las divisiones del ejército, armada y fuerza aérea. En la doctrina militar de los Estados Unidos, la EMO se referiría como Combatant Command Strategy (Joint Chiefs of Staff, 2018).

27 Un "área de operaciones" sería un espacio geográfico especifico en donde se desarrollan las operaciones militares. No debería confundirse con el concepto de 'ambiente operacional', ya que este sería la composición de condiciones, circunstancias e influencias que afectan el empleo de las capacidades y pesan en las decisiones del comandante. Si bien abarca las áreas físicas, también contemplaría los factores de los dominios y el ambiente de la información. De acuerdo con el Centro de Doctrina del Ejército (2016), el propósito de un ambiente operacional sería colaborar en el entendimiento de la totalidad de los factores y las condiciones que afectan la conducción de las operaciones, lo que permite a los líderes identificar mejor el problema, anticipar posibles resultados y entender las de diversas acciones amigas, enemigas, opositoras y neutrales, así como los efectos que estas acciones tendrían en un área de operaciones

28 Una 'orden de operaciones' sería una directiva emitida por un comandante a sus comandantes subordinados con el propósito de coordinar efectivamente la ejecución de una operación. Se diferencia de un 'plan de operaciones' en la medida en que un plan de operaciones sería una orden de operaciones a la que no se le ha asignado un tiempo de ejecución (Centro de Doctrina del Ejército, 2016).

29 Según el Centro de Doctrina del Ejército (2016), el 'arte operacional' sería el enfoque cognitivo de los comandantes y estados mayores apoyados en sus habilidades, conocimiento, experiencia, creatividad, criterio y juicio, para desarrollar estrategias, campañas y operaciones, y organizar y emplear las Fuerzas Militares de acuerdo con fines, medios y modos. 


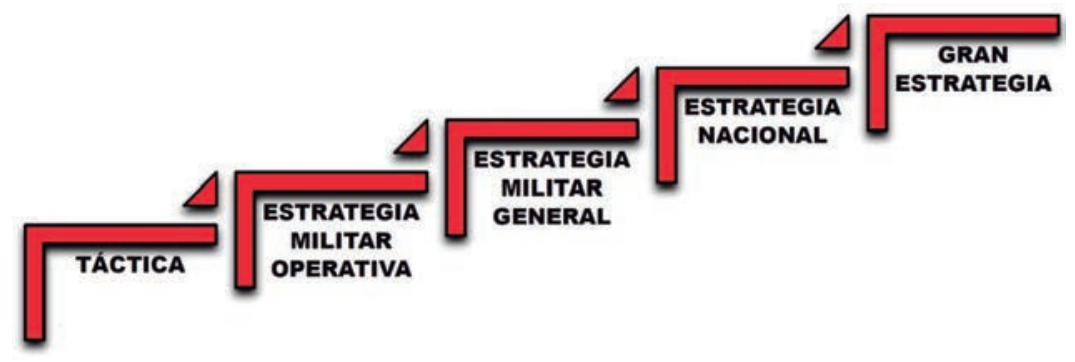

Figura 7. Niveles de la estrategia.

Fuente: elaboración propia.

Utilizando el plan de guerra y la estrategia nacional como guía, los comandantes de un teatro de operaciones, responsables de la estrategia militar operativa, desarrollarían los planes de campaña que describen la visión para integrar y sincronizar las actividades y operaciones militares, con los otros instrumentos del poder nacional, ${ }^{30}$ con el propósito de alcanzar los fines estratégicos. El plan de campaña se derivaría de la estrategia del comandante del teatro de operaciones y proporcionaría el plan de acción para implementar la estrategia en el 'terreno'. La EMO sería el puente entre la estrategia nacional y la planificación operativa conjunta, ya que orienta el desarrollo del plan de campańa.

A continuación, la Estrategia Militar General (EMG) explicaría, a través del plan de guerra, la dirección de las unidades militares más grandes en un teatro de operaciones, incluidos ejércitos y grupos de ejércitos, flotas navales y fuerzas aéreas numerosas. Prescribe cómo los instrumentos militares per se pueden lograr los objetivos que se les han fijado mediante la gran estrategia o la estrategia nacional, dentro de un determinado teatro de operaciones. Este nivel de la estrategia sería responsabilidad del comandante general de las fuerzas militares y los comandantes de su estado mayor, quienes elaborarían, a través de un plan de guerra, las directrices generales a ser llevadas a cabo por los planes de campaña y los planes de operaciones.

Concebida en la doctrina estadounidense como la National Military Strategy, la EMG proporcionaría, a una fuerza militar conjunta, un marco para proteger y promover los intereses nacionales ${ }^{31}$ del Estado. Es decir, la EMG establecería una dirección estratégica para la contribución militar en el cumplimiento de los obje-

30 El capítulo IV de este Tomo se ocupará de los instrumentos de poder nacional de los Estados.

31 Los intereses nacionales, a menudo referidos en relaciones internacionales como "razón de Estado" (por la expresión francesa raison d'État), serían aquellos objetivos y ambiciones de un país, ya sean económicas, militares, culturales o de otro tipo, necesarios para la garantía de su seguridad y defensa. Su estudio se abordará más ampliamente en el capítulo II de este volumen. 
tivos de la estrategia nacional y la gran estrategia. La EMG suministraría un marco general estratégico militar que informaría mejor la planificación de los recursos y las prioridades de asignación, la distribución del riesgo y el desarrollo de la fuerza conjunta; además, reconocería los desafíos planteados por un entorno de seguridad en evolución, abordándolos a través de un enfoque integral y global de planificación, operaciones y desarrollo de capacidades, que permita conservar la ventaja competitiva frente a adversarios potenciales (Joint Chiefs of Staff, 2018).

En otras palabras, la EMG aplicaría el instrumento militar del poder nacional para alcanzar los fines estratégicos de la estrategia nacional y la gran estrategia, razón por la cual toda EMG debería ser compatible y complementaria a la estrategia nacional. En este sentido, el desafío fundamental para cualquier estratega militar sería: primero, definir los objetivos que ayudarán a alcanzar los fines estratégicos del Estado; segundo, desarrollar un plan para alcanzar dichos objetivos; y tercero, asegurar la compatibilidad del instrumento militar con los otros instrumentos del poder nacional. Por último, tanto la EMO como la EMG corresponderían al nivel operacional de la guerra. De acuerdo al Centro de Doctrina del Ejército de Colombia (2016),

el nivel operacional unifica el empleo táctico de las fuerzas con los objetivos estratégicos nacionales y militares a través del diseño de campañas y operaciones mayores. Determina cómo, cuándo, dónde y con qué propósito los comandantes emplean grandes esfuerzos para conseguir los fines asignados. Se secuencian y sincronizan batallas, combates y otras operaciones (como la atención de desastres y el apoyo a la autoridad civil) para lograr resultados operacionalmente significativos. (p. 44)

Posteriormente se encontraría la Estrategia Nacional (EN), a cargo de la rama ejecutiva. La EN orquestaría los instrumentos del poder nacional para asegurar los objetivos políticos y estratégicos del Estado, a través de una estrategia de seguridad y defensa nacional (ESDN) o National Security Strategy (según la doctrina estadounidense). Usualmente, una ESDN describiría las principales preocupaciones de seguridad nacional y cómo planearía lidiar con ellas el Estado. En este sentido, es importante señalar que los estrategas de seguridad nacional dependerían de instituciones y actores seleccionados para asegurar los objetivos de la política nacional, a través del empleo de instrumentos del poder nacional (militar, económico, diplomático, entre otros). Por ende, cada instrumento de poder nacional comprendería un conjunto de capacidades disponibles para el estratega. ${ }^{32}$ La EN también podría

32 Por ejemplo, el instrumento militar giraría en torno al empleo de capacidades tales como la cooperación en materia de seguridad; habilitación de la fuerza (que da credibilidad a la amenaza del uso de la fuerza); o el uso real de la fuerza (si las capacidades, influencia o amenazas no lograsen los objetivos deseados). En el capítulo IV se ampliarán las formas y estrategias del empleo del poder de los Estados. 
describir los distintos logros que son requeridos para la elaboración de los objetivos estratégicos. De acuerdo con el Joint Chiefs of Staff (2018), la coherencia de la estrategia resultaría de un estrecho vínculo entre los intereses nacionales en juego, los objetivos de política perseguidos para garantizar los intereses nacionales y los fines estratégicos, reforzados por aquellos objetivos que inevitablemente alcanzarían el deseado estado final de la estrategia.

Los formuladores de políticas articularían sus percepciones de los intereses nacionales en objetivos de política que, en algunos casos, podrían llegar a ser demasiado amplios como para que sirvan de objetivos concretos para una estrategia. No obstante, estos objetivos de política se utilizarían en la formulación de los objetivos de la estrategia. Los objetivos estratégicos definirían el resultado que el estratega creería preservará, protegerá o promoverá los intereses nacionales. Por ende, identificar los intereses nacionales sería un desafío estratégico en sí mismo y el punto de partida para cualquier estrategia y política en seguridad y defensa. Adicionalmente, los estrategas deberían distinguir conceptualmente aquellas instituciones que ejercen los instrumentos del poder nacional de los instrumentos mismos. Por ejemplo, si bien las fuerzas militares son aquellas organizaciones facultadas para el manejo del instrumento militar de poder, si un miembro de la Policía nacional de Colombia eliminara a un terrorista, estaría ejerciendo una fuerza letal usualmente atribuida al instrumento militar de poder.

La EN como la EMG harían parte del nivel estratégico de la guerra, ya que, según el Centro de Doctrina del Ejército de Colombia (2016),

el nivel estratégico lo establecen los objetivos nacionales, multinacionales y del teatro. Deriva una idea fundacional o un conjunto de ideas para el empleo de los instrumentos del poder nacional de una manera sincronizada e integrada en el cumplimiento de estos objetivos. Secuencia las iniciativas y define los límites de riesgo en las operaciones. También proporciona la capacidad [medios] que se utilizan para lograr estos fines. La estrategia militar, derivada de la política y estrategia nacional y enmarcada por la doctrina, proporciona un marco para la realización de las operaciones. El nivel estratégico de la guerra es principalmente del ámbito del liderazgo nacional y se expresa en la doctrina conjunta y las estrategias de seguridad, defensa y militares (p. 44)

Como ya se ha mencionado, la EN involucraría todos los elementos del poder nacional que, a su vez, podrían dividirse convenientemente en las categorías política, económica, social y militar (figura 8).

El eje del plano horizontal de la EN sería el instrumento del contínuum vertical de la guerra (figura 9). Por lo tanto, la combinación de fines, medios y modos a 


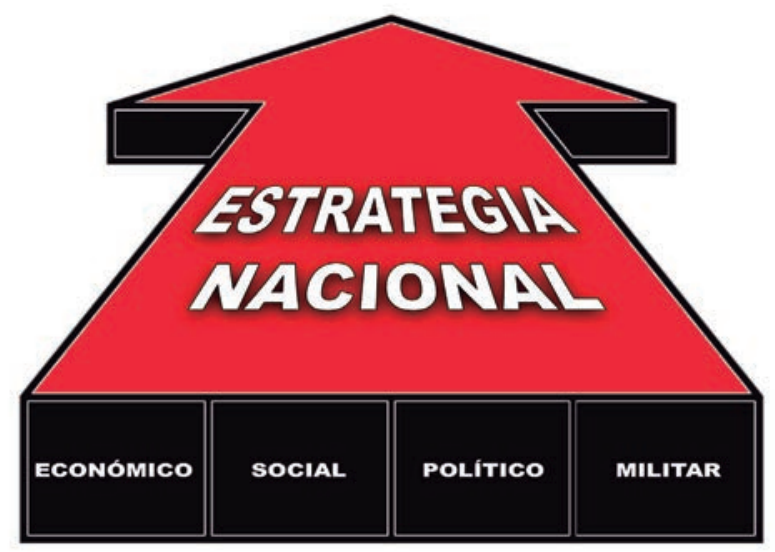

Figura 8. La EN: el plano horizontal.

Fuente: elaboración propia.

nivel de la EMG afectarían directamente (y se verían afectados), por el mismo paradigma que opera en cada nivel del contínuum vertical. A la complejidad se agrega la interacción en el plano horizontal de la EMG con las otras estrategias derivadas de los elementos del poder nacional, mientras cada una opera dentro de su propio paradigma estratégico y contribuye al gran diseño de la EN, a medida que esa estrategia evolucionaria en sí misma, con su propia combinación de fines, medios y modos.

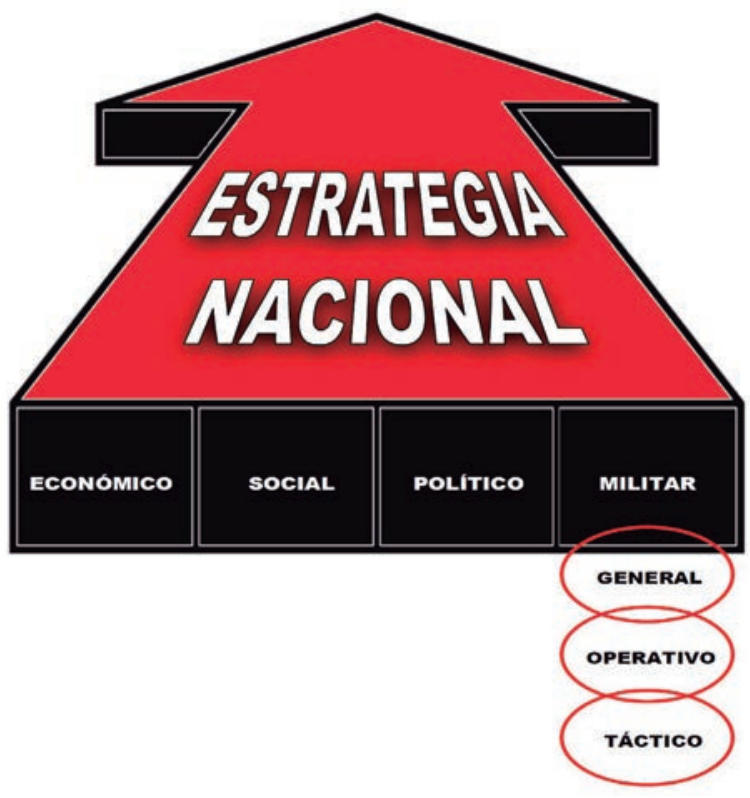

Figura 9. La EN y el contínuum vertical de la guerra.

Fuente: elaboración propia. 


\section{La Gran Estrategia}

En la parte superior de los niveles de la estrategia se encontraría la Gran Estrategia (GE) o Grand Strategy. Así como existiría un nivel táctico, operacional y estratégico, también existiría un gran nivel de estrategia. La GE podría ser la forma más elevada del arte de gobernar, ya que, reducida a su esencia, sería la arquitectura intelectual que le da estructura a la política exterior de un Estado (Brands, 2014). En este orden de ideas, la GE apuntaría a asegurar y avanzar los intereses fundamentales de una nación a largo plazo, aquellos por los cuales cualquier Estado gastará, legislará, amenazará o luchará para defender a lo largo del tiempo. Showalter (1991) asegura que toda GE sería mejor entendida como "el cálculo de las relaciones entre medios, fines y voluntad" (p. 108), si se tiene en consideración que los 'medios' podrían ser los activos tangibles e intangibles (capacidades de poder), con los que cuenta o podría llegar a contar un Estado para obtener ventajas comparativas y competitivas en un entorno mundial altamente globalizado; los 'fines' serían los objetivos nacionales de mediano y largo plazo que un Estado haya establecido; y la 'voluntad' se entendería como la decisión política y consensuada del más alto nivel, que conllevaría a cierto grado de institucionalización en el tiempo, a través de objetivos nacionales y políticas públicas. De tal modo que la GE crearía las condiciones para la estrategia y también la guiaría.

Por tales razones Kennedy (1987) consideraría que la clave de toda GE se basa en la política, es decir, en la voluntad de los líderes de la nación para juntar a todos los elementos militares y no militares para la preservación y engrandecimiento de los mejores intereses de largo plazo. Asimismo, Parker (1998) establece que toda GE abarcaría

las decisiones de un determinado Estado sobre su seguridad general (la amenaza que percibe, las maneras de enfrentar a las mismas y los pasos a tomar para que coincida el fin con los medios), y cada uno implica la integración de los objetivos políticos, económicos y militares generales del Estado, tanto en tiempo de paz como en tiempo de guerra, para preservar los intereses de largo plazo, incluso la administración de los fines y los medios, la diplomacia y moral nacional y la cultura política, tanto en la esfera militar como civil. (p. 1)

En consecuencia, la GE sería un tipo de estrategia muy específica, que identificaría y articularía los objetivos de seguridad de un actor político en un momento determinado, y describiría cómo se lograrían utilizando una combinación de instrumentos de poder, incluidos instrumentos militares, diplomáticos y económicos. Es decir, las GE abordarían los problemas difíciles de la política nacional, en aquellas 
áreas donde los factores políticos, económicos, sociales, psicológicos y militares se superpondrían.

\subsection{Evolución de un concepto}

Según Gaddis (2018), la GE sería la "alineación de aspiraciones potencialmente ilimitadas con capacidades necesariamente limitadas" (p. 26). Con base en la definición anterior, la necesidad de tal alineación podría remontarse a los Estados primitivos, que descubrirían cómo obtener algo que querían, usando cualquier medio que estuviera disponible. Tal sería el caso, por ejemplo, de las guerras médicas (490 a. C.- 478 a. C.), una serie de conflictos entre el Imperio aqueménida de Persia y las ciudades-Estado de Grecia. En el desarrollo de dichas guerras, Jerjes había traído consigo, a través del Helesponto, todas las capacidades militares del Imperio persa, pero no una 'gran estrategia'; por ende, si sus aspiraciones eran sus capacidades, ¿por qué molestarse en alinearlas?

En efecto, creyéndose fuerte en todos los aspectos, Jerjes no tenía nada en reserva y terminaría perdiendo en una secuencia de malas decisiones más de novecientos trirremes y un cuarto de millón de hombres (Hanson, 2013). Los griegos, por el contrario, solo conocían la escasez, ya que, a diferencia de los persas cuyo imperio se extendía desde el Egeo hasta la India, ocupaban una pequeña península geográficamente accidentada que fragmentaba los recursos y resistía la autoridad. En consecuencia, las ciudades griegas tenían que protegerse a sí mismas, sin ningún rey de reyes con la capacidad de unificar y coordinar los esfuerzos de todos los pueblos en Grecia (Rahe, 2015). Si bien se construirían alianzas entre las ciudades-Estado, las obligaciones eran vagas y las lealtades frágiles y cambiantes, lo que convertiría a Grecia en un invernadero para las rivalidades, pero también, por lo mismo, para las grandes estrategias (Kagan, 1991).

No obstante, si como práctica la GE podría rastrearse hasta los primeros inicios de la civilización humana, como concepto sería una invención moderna; así como los alemanes y rusos podrían llegar a reclamar la autoría de los avances teóricos en el nivel operativo de la guerra, entonces Gran Bretaña podría llegar a reclamar el desarrollo conceptual y teórico de la GE. Sir Julian Corbett, el mayor general John Frederick Charles Fuller y Basil Liddell Hart, estarían a la vanguardia británica en el desarrollo del concepto de GE. Por ende, la GE vendría a ser una invención conceptual del siglo xx, a pesar de que la expresión ya hubiese sido utilizada en el siglo XIX, en un sentido orientado a la estrategia militar en la tradición jominiana, con su énfasis en las líneas de operación y la captura del territorio (Ward, 1859; Sherman, 1888). 
En su obra de 1906, titulada Strategical Terms and Definitions Used in Lectures on Naval History, el historiador naval Sir Julian Corbett dividiría la estrategia en "estrategia mayor" y "estrategia menor"; la estrategia mayor (o gran estrategia), se referiría a los recursos completos destinados por el Estado para la guerra (militares, económicos, diplomáticos y políticos), mientras que la estrategia menor se centraba en los planes operativos. Corbett (1909) sugeriría que

la estrategia mayor [siempre con respecto al objeto ulterior], tendría para su provincia el plan de la guerra, el cual incluiría: 1). La selección de los objetos inmediatos o primarios a los que se apuntase para alcanzar el objeto ulterior; 2). La selección de la fuerza que se utilizaría, es decir, que determinaría las funciones relativas de las fuerzas navales y militares. (p. 1)

Curiosamente, la concepción de GE de Corbett se mantendría orientada hacia lo externo. A medida que desarrollaba el concepto, Corbett (1911) restringió los deberes no militares de la estrategia mayor a inspeccionar activamente "la posición político-diplomática del país [de la cual depende la acción efectiva del instrumento], así como su posición comercial y financiera" (p. 117). En opinión de Corbett, a pesar de la relación íntima que tenía con el comercio y las finanzas, la GE se preocupaba más por ellos como instrumentos y como objetivos en la guerra, particularmente con respecto a sellar alianzas durante la guerra, en lugar de su utilidad doméstica para desarrollar los medios para hacer la guerra.

Posteriormente, el mayor general Fuller, del ejército británico, basándose en la experiencia de guerra 'total' de la Primera Guerra Mundial, introduciría nuevamente el concepto en 1923, al establecer diferentes tipos de estrategias: gran estrategia, estrategia mayor y estrategia menor. Para Fuller (1923), la GE sería "la utilización de las energías nacionales para los fines de guerra” (p. 6), y debía llevarse a cabo al más alto nivel de gobierno e implicaba la coordinación de las fuerzas materiales y sociales del Imperio británico para estar bien preparado para cualquier conflicto futuro. Por ende, la GE involucraba "los aspectos militares de una nación, la moral de la población civil, los recursos comerciales e industriales [...], y el elemento del espíritu" (Fuller, 1923, p. 214).

Sin embargo, el mayor papel de la GE no sería para tiempos de guerra sino para tiempos de paz:

Por paradójico que pueda parecer, el tiempo de descanso del gran estratega es durante la guerra, porque es durante la paz que trabaja y labora. Durante el tiempo de paz no solo calcula los recursos en hombres, suministros y fuerzas morales de todos los enemigos posibles, sino que, después de haberlos pesado, él, insospechado por el enemigo, los socava por un plan. (Fuller, 1923, p. 220) 
El concepto de las GE ganaría posteriormente mayor popularidad en las décadas de los cuarenta y los cincuenta, como consecuencia de la Segunda Guerra Mundial, cuya conducta exitosa requería que los países aliados coordinaran iniciativas diplomáticas, económicas, políticas y militares a una escala global. También se debería al aporte teórico de Liddell Hart (1929), quien diseminaría el concepto a un público más amplio, al definir con mayor claridad el concepto de la GE:

El papel de la "gran estrategia" es coordinar y dirigir todos los recursos de una nación hacia la consecución del objetivo político de la guerra: el objetivo definido por la política nacional. La gran estrategia debería tanto calcular como desarrollar los recursos económicos y el poder humano de la nación para sostener los servicios de combate. Así también con los recursos morales, para fomentar y fortalecer la voluntad de ganar y de perdurar [...]. Y debe regular la distribución de poder entre los diversos Servicios, y entre los Servicios y la industria. Tampoco es esto todo, porque el poder [militar] de combate no es más que uno de los instrumentos de la gran estrategia. Debe tener en cuenta y aplicar el poder de la presión financiera, la presión diplomática, la presión comercial y, sobre todo, la presión ética para debilitar la voluntad del oponente [...]. Aunque el horizonte de la estrategia está limitado por la guerra, la gran estrategia mira más allá de la guerra, hacia la paz subsiguiente. (Lidell Hart, 1929, p. 150)

Liddel Hart afirmaría que el propósito de la gran estrategia no era simplemente convertir todas las capacidades disponibles del Estado para lograr la victoria, sino también garantizar que el desembolso de los recursos no superaría la relación costo-beneficio. Es decir, derrotar a un enemigo no era un fin en sí mismo, era, simplemente, el medio para asegurar una paz mejor para el Estado y su sociedad. Según Liddel Hart, esta distinción no era trivial ya que la búsqueda del triunfo militar podría fácilmente llegar a ser tan absorbente que, finalmente, dejaría al Estado victorioso incluso más débil de lo que había sido al comienzo de la guerra, como eventualmente ocurriría en la Primera Guerra Mundial (con la victoria pírrica de los aliados), caso en el que el precio que se pagaría en vidas humanas y otros recursos terminaría negando un auténtico sentido de logro o beneficio (Álvarez et al., 2017). En consecuencia, la GE "no solo debería combinar los diversos instrumentos [del Estado], sino también regular su uso para evitar daños al futuro estado de paz, para su seguridad y prosperidad" (Liddell Hart, 1954, p. 336). Por lo tanto, la GE sería un concepto de orientación civil, debido a su gestión de los recursos y sus principios, contrarios a los de la estrategia militar.

El actual pensamiento estratégico de los Estados Unidos reflejaría este legado de Liddell Hart. En efecto, a partir del Acta Goldwater-Nichols, para la reorgani- 
zación del Departamento de Defensa de 1986, se ha requerido que cada gobierno de los Estados Unidos publique regularmente la ESDN. El término se ha convertido en sinónimo de la GE en los Estados Unidos, aunque esta sería una GE para el propósito específico de "desarrollar, aplicar y coordinar los instrumentos del poder nacional para lograr objetivos que contribuyan a la seguridad nacional” (Kohout, 1995, p. 362). Strachan (2011) ha insistido en que la calidad más limitada y de corto plazo de la EN, no debería ser sustituida con la orientación más amplia y de más largo plazo de la gran estrategia, ya que lo que Estados Unidos llamaría "Gran Estrategia”, podría denominarse 'Estrategia Nacional' en otros Estados.

Varios politólogos opinarían que la GE es un deliberado y detallado plan para la acción. Por ejemplo, Feaver (2009) afirmaría que la "gran estrategia se refiere a la recopilación de planes y políticas que comprenden el esfuerzo deliberado del Estado para combinar herramientas políticas, militares, diplomáticas y económicas para promover el interés nacional de ese Estado [...]. Implica acción intencional, es decir, lo que los líderes piensan y quieren” (p. 18). Por su parte, Walt (1989) sustituiría la palabra 'plan' por "teoría” y argumentaría que "la gran estrategia de un Estado sería su plan para 'asegurarse’. La gran estrategia identificaría los objetivos que deben alcanzarse para producir seguridad y describiría las acciones políticas y militares que se cree podrían conducir a este objetivo" (p. 6). De manera similar, Krasner (2010) sugiere que la GE estaría "diseñada" y detallaría los recursos "diplomáticos, burocráticos, ideacionales, militares y económicos asignados para políticas específicas" (p. 2). Aunque existirían reservas a la noción de que la GE se refiere a un tipo de plan detallado que pueden producir los estadistas reunidos alrededor de un mapa, este concepto de GE tendría una larga tradición intelectual, representado en la literatura contemporánea y en el discurso de política pública. Como una abreviatura, este concepto de GE se podría considerar como un 'gran plan'.

Los académicos que rechazarían la noción de GE como un 'gran plan', a menudo lo harían a favor de una segunda conceptualización de la GE como un principio o conjunto de principios 'organizadores'. En este sentido, la diferencia entre un plan y un principio dependería del nivel de detalle, es decir, un plan es más detallado que un principio.

Si definimos la gran estrategia, erróneamente, como simplemente un plan prefabricado, llevado a cabo al pie de la letra contra toda resistencia, entonces claramente ningún presidente y probablemente ningún líder mundial alguna vez haya tenido tal estrategia. Pero si adoptamos una definición menos estricta, vemos que todos los presidentes necesariamente toman decisiones y decisiones en relación con la política de seguridad nacional y extranjera de los Estados Unidos, basándose al menos parcialmente en sus propios supuestos preexistentes. (Dueck, 2015, p. 5) 
En lugar de denotar planes detallados, la GE sería para los académicos afiliados a esta tradición, una "guía general" (Martel, 2015), una "visión estratégica básica" (Kennedy, 1991), o "doctrinas generales de política exterior" (Edelstein y Krebs, 2015). Por ende, se podría pensar en este concepto de GE usando el término de "grandes principios".

En el tercer uso del concepto de GE, esta se referiría a un patrón de comportamiento. El patrón de comportamiento no se evidenciaría a partir de la existencia de un plan o principio organizador, ya que el patrón sería en sí mismo la GE. Esto podría llegar a parecer extraño para algunos académicos acostumbrados a pensar en la GE como un principio organizativo de carácter consciente; sin embargo, "todos los Estados tendrían una gran estrategia, sea que lo sepan o no" (Luttwak, 2009, p. 409). La GE sería para Luttwak, el empleo de los recursos del Estado, incluida la fuerza militar, la diplomacia y la inteligencia, que interactúan con el empleo de estos recursos por parte de otros Estados. De manera similar, Mintzberg (2007) argumentaría que, en el ámbito corporativo, no sería del todo correcto la noción de que la estrategia comercial es un plan formal ideado por altos directivos y luego implementado por una organización; en cambio, postula un concepto alternativo en el que la estrategia sería "un patrón, consistente en un comportamiento en el tiempo" (p. 5). Por lo tanto, en aras de la claridad en el estudio de la GE, se podría pensar en este tercer concepto usando el término de "gran comportamiento".

\subsection{Características de la Gran Estrategia}

Toda GE estaría destinada a guiar el análisis y el pensamiento estratégico, al proporcionar un útil marco cognitivo; sin embargo, las características que distinguen la GE de otros tipos de estrategia han sido raramente examinadas (Layton, 2012), hasta el punto que la GE usualmente se confunde y se combina con la EN. En principio, la GE se distinguiría por su alcance más amplio; si la estrategia es "un plan para la aplicación de unos recursos en orden de alcanzar unos objetivos" (Deibel, 2007, p. 5), la GE sería más que la aplicación de unos recursos. También implicaría el desarrollo de los recursos y su eficiente asignación por parte del Estado; en efecto, la GE tendría que ver con la consecución de la mano de obra, el dinero y el material necesarios para construir y mantener los medios necesarios.

Dependiendo de la GE, se podría acceder a esos recursos a nivel nacional o a nivel internacional, de fuentes privadas o gubernamentales, o en una compleja combinación de las anteriores. Es importante destacar que una GE también debería construir la legitimidad y la persuasión necesarias para implementarse con éxito. 
Es decir, más que aplicación de los recursos, la GE proporcionaría los recursos o medios utilizados por la estrategia. Esta sería una diferencia crucial que haría que la GE sea diferente no solo de la estrategia, sino también a la política exterior y el propio arte de gobernar.

Sin embargo, la GE también se ocuparía de la aplicación de recursos, pero de una manera más sofisticada que los otros tipos de estrategia. En primer lugar, en la GE los medios utilizados serían integrales y abarcarían una amplia gama de instrumentos de poder nacional, en lugar de centrarse en un solo tipo de instrumento, como lo hace, por ejemplo, la EMG; este poder nacional sería mucho más amplio, ya que incluiría las fuentes externas comerciales y gubernamentales que, generalmente, también se utilizarían como apoyo a los objetivos a alcanzar. En segundo lugar, la GE se ocuparía de integrar la aplicación de estos diversos medios con su creación y asignación en un todo coherente y cohesionado, razón por la cual la esencia de la GE sería su naturaleza integradora.

Por consiguiente, en un sentido conceptual, la Ge sería un sistema, es decir, un conjunto de elementos interdependientes donde el cambio en algunos, o en sus relaciones, produciría cambios en todo el sistema. Con base en la teoría sistémica, los resultados de un sistema no se podrían entender sumando las unidades o sus relaciones (Álvarez y Rodríguez, 2018), por lo que una GE solo podría entenderse en su totalidad y no como un conjunto de elementos o unidades desagregados. Milward (1979) demostraría que las GE de los principales actores de la Segunda Guerra Mundial no solo terminarían impactando a sus sociedades, sino que las GE adoptadas también serían influenciadas y modeladas por sus respectivas bases domésticas. Con base en el concepto de 'síntesis estratégica', Milward (1979) establecía que si un Estado lograba un equilibrio deliberado entre las demandas de su GE elegida y la capacidad de la base doméstica para satisfacer estas demandas, sería porque estaría tomando en cuenta la dimensión externa de la GE (aplicación de los medios) y la dimensión doméstica de la GE (creación de los recursos o medios de poder).

Al aplicar la distinción de "síntesis estratégica" de Milward a la GE estadounidense durante la Guerra Fría, Friedberg (2000) determinaría que mientras los Estados Unidos desarrollaron progresivamente una gran síntesis estratégica, la Unión Soviética no lo haría. Según Friedberg (2000), como consecuencia de una fuerte cultura política estatista, la Unión Soviética elegiría una GE que la convirtió en un garrison state, donde se daría primacía a la preparación militar, en detrimento significativo de la sociedad y el colapso final del Estado. En contraste, y con una ideología antiestatista, Estados Unidos sería más prudente, lo que eventualmente 
le llevaría a lograr un mejor equilibrio entre la preparación militar, la prosperidad social y el crecimiento económico de largo plazo.

Para la década de los cincuenta, Estados Unidos se había convertido en un Estado 'contractual' que limitaba la extracción y la movilización de recursos a áreas muy específicas de la economía, y dependía de la iniciativa privada para la investigación, el desarrollo y la fabricación de armamentos necesarios. Por ende, la GE estadounidense, a medida que evolucionaba, imponía una carga menor a su sociedad, dándole una mayor resistencia y solidez en contraste con la cada vez más frágil Unión Soviética. En otras palabras, mientras que la síntesis estratégica soviética sería fatalmente defectuosa, Estados Unidos equilibraría mejor las demandas de la GE y la creación de los medios necesarios. No en vano, se consideraría a la era Truman como la edad de oro de la GE estadounidense, es decir, una época de gran visión estratégica en la que los funcionarios públicos establecían políticas de largo plazo con el fin de contener el poder soviético y estabilizar el orden global.

Con base en lo anterior, algunos pensadores estratégicos han limitado la GE al ámbito de las grandes potencias, las cuales, consideran, serían las únicas capaces de diseñar una 'gran estrategia'. No obstante, como la GE sería el nivel más alto de estrategia, y no tanto una función específica de un tipo particular de arreglo político (Layton, 2012), la integración de la creación de las capacidades de poder con los instrumentos de poder, así como de la preservación del equilibrio de los medios con los fines, terminaría constituyéndose en un factor crucial para todos, incluso para aquellos Estados con recursos limitados. Del mismo modo, Schmidt (2008) argumenta que la GE se podría considerar como "una visión general de los objetivos en seguridad nacional de un Estado, así como una determinación de los medios más apropiados para lograr estos objetivos" (p. 164). Asimismo, el autor afirma que existirían tres pasos para el diseño de toda GE: 1) determinar los objetivos de seguridad; 2) identificar la fuente principal de amenazas (internas y externas) a estos objetivos y 3) determinar los recursos clave políticos, económicos y militares empleados para alcanzar los objetivos de seguridad nacional. Schmidt (2008) daría cuenta de que estos procesos serían replicables en todos los Estados, incluso con capacidades diferentes:

Los funcionarios de política exterior en todos los Estados pasan por un proceso similar, aunque las grandes estrategias resultantes tienden a ser bastante diferentes unas de otras [...]. También es una función de las distintas capacidades que poseen los Estados, así como otra serie de factores que determinan el poder nacional, incluyendo su tamaño geográfico y su ubicación. Las grandes potencias, por ejemplo, suelen tener una noción más amplia de la seguridad y se enfrentan proporcionalmente a más grandes amenazas que los Estados más débiles. (p. 164) 
Schmidt identifica que todos los Estados, grandes y débiles, llevarían a cabo alguna forma de GE que busque la garantía de la seguridad contra una multiplicidad de amenazas. En este orden de ideas, la utilidad que tendría el diseńo de una GE para Colombia es enorme, si se toma en cuenta que toda GE buscaría establecer un estado de orden preferido en el futuro. Kassab (2018) la concebiría como un mapa de ruta conceptual, consistente en una serie planificada de acciones sucesivas para crear un mundo preferido en el futuro; en efecto, la Ge proporcionaría "los ingredientes clave de claridad, coherencia y consistencia de las políticas públicas, a lo largo del tiempo" (Foster, 1985, p. 14). De acuerdo con Metz (2008), la GE "implicaría un orden extendido en tiempo y espacio [...]. Intentaría imponer coherencia y previsibilidad en un entorno intrínsecamente desordenado, compuesto por entidades [del Estado] que piensan, reaccionan, compiten y entran en conflicto" (p. XVIII). Con base en lo anterior, la GE no parecería ser apropiada para periodos de crisis de corto plazo, ya que el desarrollo de los medios llevaría algún tiempo. Además, en una crisis, el objetivo sería regresar al statu quo anterior, o al menos estabilizar la situación presente, antes que crear un nuevo futuro. Además, una crisis también podría implicar solo uno o dos instrumentos del poder nacional (bien sea económica, militar, diplomática, etc.), en lugar de una gran integración estratégica de todas ellas.

Si la GE se podría definir simplemente como el uso del poder para la seguridad y defensa del Estado, este nivel de la estrategia de ninguna manera se limitaría a las instituciones militares, por el contrario, abarcaría todas las formas de poder nacional. Por ende, cualquier evaluación para el diseño de una GE debería comenzar con una mirada al entorno de seguridad y a las amenazas a los valores, creencias e intereses vitales del Estado, sin sobreestimarlos o menospreciarlos. Una forma de comprender la GE consistiría en analizar el comportamiento del Estado a largo plazo, tal como lo definen los intereses fundamentalmente perdurables a la seguridad, y cómo el Estado los protege y los hace progresar con el tiempo. Esto significaría, en cierto modo, que lo que 'hace' el Estado sería más importante que lo que 'dice'; en consecuencia, la GE trascendería los pronunciamientos en torno a los temas de seguridad de los partidos políticos o de las administraciones gubernamentales de turno.

Si se toma en cuenta que la GE integraría las funciones del desarrollo y la asignación de los recursos, con la aplicación de los medios con el fin de alcanzar los objetivos propuestos, sería relevante mencionar que solo existiría una comprensión de estas tres áreas separadas en un nivel específico del Estado. Incluso Luttwak (2001) establecería que solo en el más alto nivel del Gobierno se encontraría el 
conocimiento apropiado y la capacidad para determinar y dirigir la GE; sin embargo, a medida que un gran concepto estratégico descendiese en la jerarquía gubernamental, los objetivos y las metas se definirían con cada vez mayor precisión, para una adecuada coordinación de acciones en los niveles subordinados.

\section{Cultura y pensamiento estratégico en seguridad y defensa: ¿condiciones para una gran estrategia?}

La cultura estratégica podría ayudar en la comprensión académica y en el análisis de las políticas de seguridad y defensa de diversos actores en el ámbito internacional. En efecto, de acuerdo a Baylis y Wirtz (2016), "reconocer el impacto de diversas culturas estratégicas parece especialmente pertinente en el campo de la seguridad del siglo xxI" (p. 7). Para Johnston (1995b) la cultura estratégica sería el "medio ideacional que limita las elecciones de comportamiento, de las cuales uno podría derivar predicciones específicas sobre la elección estratégica”, mientras que para Booth y Trood (1999), la cultura estratégica podría definirse como "un conjunto distintivo y duradero de creencias, valores y hábitos con respecto a la amenaza y el uso de la fuerza, que tienen sus raíces en influencias fundamentales como el entorno geopolítico, la historia y la cultura política” (p. 15).

Algunos académicos (Glenn, et al., 2004; Johnson et al., 2009; Lantis, 2014), considerarían que la cultura tiene un profundo impacto en la toma de decisiones estratégicas, razón por la cual en los últimos años se ha renovado el interés académico y normativo por explorar su papel en la seguridad internacional. Por lo tanto, puede ser importante tratar de salirse de la propia perspectiva cultural para abrazar la posibilidad de que otras culturas como, por ejemplo, las no occidentales, puedan exhibir diferentes formas de pensamiento y comportamiento, ya que

la consideración de la cultura como "una forma de vida" de una nación implica también su visión del mundo y de otras naciones. Así, cada pueblo actúa en el mundo sobre la base de cómo cree estar en él y de cómo imagina que están los otros pueblos. (Álvarez, 2017b, p. 42)

Esto se apartaría de las interpretaciones del comportamiento de la política de seguridad como una función de las oportunidades materiales y las limitaciones en el entorno externo, y ofrece una ruta para reconocer formas en que las influencias culturales, simbólicas y normativas impactan las motivaciones de los Estados y sus líderes (Glenn, 2009, p. 523). 
Todas las culturas condicionan a sus miembros a pensar de ciertas maneras, mientras que al mismo tiempo proporcionan respuestas preestablecidas a situaciones determinadas. Por lo tanto, la cultura limita nuestras percepciones y el rango de opciones que tenemos para responder a los eventos. Sin embargo, cuando una sociedad experimenta un choque severo o un desastre mayor, obliga a esa cultura a ser más abierta, ya que se vuelve momentáneamente susceptible a nuevas explicaciones, nuevos paradigmas y nuevas formas de pensar, todo en busca de comprensión y mitigación del impacto que les ha sucedido. (Johnson et al., 2009, pp. 5-6)

La Unesco (2009), en su Declaración Universal sobre la Diversidad Cultural, afirmaría que la cultura tendría que ser considerada como el "conjunto de características espirituales, materiales, intelectuales y emocionales propias de una sociedad o grupo social", y que "abarca, además del arte y la literatura, los estilos de vida, las formas de convivencia, los sistemas de valores, las tradiciones y las creencias" (p. 56). Por lo tanto, la mayoría de los que usan el término 'cultura' tenderían a argumentar, explícita o implícitamente, que los diferentes Estados tendrían diferentes preferencias estratégicas predominantes que están arraigadas en las experiencias tempranas o formativas del Estado, las cuales estarían influenciadas, en cierto grado, por las características filosóficas, políticas, culturales y cognitivas del Estado y sus élites.

\subsection{Evolución de los estudios en cultura estratégica}

La idea de que la cultura podría influir en los resultados estratégicos se evidenciaría por primera vez en obras clásicas como las de Tucídides (1986), Sun Tzu (2012) y Clausewitz (1989). En efecto, Clausewitz identificaría la estrategia de guerra como una prueba de fuerzas morales y físicas; argumentaba que el objetivo de la estrategia era, más que la derrota física del enemigo en el campo de batalla, la eliminación de la moral del adversario. No obstante, la Segunda Guerra Mundial provocaría una nueva ola de investigaciones sobre el carácter nacional distintivo de los países, que estaban enraizados en el lenguaje, la religión, las costumbres y la interpretación de los recuerdos comunes. Los académicos y estrategas comenzarían a sentir curiosidad acerca de cómo el carácter nacional de un país podría llevar a los Estados a luchar en guerras de maneras diferentes. Por ejemplo, algunos buscarían entender cómo la cultura japonesa fomentaba un espíritu de autosacrificio, evidenciada en los ataques kamikaze contra buques de guerra estadounidenses o en las batallas a muerte en las remotas islas del Pacífico Sur.

Para Parsons (1951), la cultura se compondría de "códigos interpretativos" que incluirían lenguaje, valores e incluso creencias sustantivas como el apoyo a la 
democracia o la inutilidad de la guerra. Por su parte, Geertz (1973) argumentaría que la cultura se compondría de "un patrón de significados transmitidos históricamente, encarnados en símbolos y un sistema de concepciones heredadas expresadas en forma simbólica por medio de las cuales los hombres se comunican, perpetúan y desarrollan su conocimiento y actitudes hacia la vida" (p.32). Sin embargo, Almond y Verba (1965) generarían interés en el estudio comparativo de la cultura política, definiéndola como el "subconjunto de creencias y valores de una sociedad que se relaciona con el sistema político” (p. 11). Por ende, la cultura política incluía un compromiso con valores como los principios y las instituciones democráticas, las ideas sobre la moral y el uso de la fuerza, los derechos de individuos o colectivos, y las predisposiciones hacia el rol de un Estado en el contexto mundial. En consecuencia, la cultura política se manifestaría al menos en tres niveles: 1) el cognitivo, que incluiría las creencias empíricas y causales; 2) el evaluativo, que consistiría en valores, normas y juicios morales y 3) lo expresivo o afectivo, que abarcaría apegos emocionales, patrones de identidad y lealtad, y sentimientos de afinidad, aversión o indiferencia (Duffield, 1999).

No obstante, Snyder (1977) introduciría la cultura en los modernos estudios de seguridad y desarrollaría una teoría de la cultura estratégica ${ }^{33}$ para interpretar la doctrina nuclear soviética, ya que el enfoque predominante de la estrategia nuclear había sido modelado, hasta entonces, por tratados econométricos de utilidad racional. ${ }^{34}$ El enfoque alternativo de Synder para analizar la interacción nuclear soviético-estadounidense se centraría en lo que él consideraba eran las diferencias culturales estratégicas distintivas entre los dos Estados. El trabajo de Snyder sería influenciado por estudios previos en asuntos militares que destacaban las distinciones culturales, esto incluía los trabajos de Liddell Hart (1932) y Wrigley (1973). En este orden de ideas, Snyder sugeriría que las élites articulaban una cultura estratégica única relacionada con asuntos de seguridad militar, producto de una manifestación más amplia de la opinión pública, socializada en un modo distintivo de pensamiento estratégico. Snyder concluiría que los militares soviéticos exhibían una preferencia por el uso preventivo y ofensivo de la fuerza, y que los orígenes de este comportamiento podían encontrarse en la historia de inseguridad y control autoritario de los rusos.

33 Snyder (1977) sería el primero en acuñar el término 'cultura estratégica' como la "suma total de ideales, respuestas emocionales condicionales y patrones de comportamiento habitual, que los miembros de la comunidad estratégica nacional han adquirido mediante instrucción o imitación” (p. 9).

34 Estados Unidos y la Unión Soviética se caracterizaron, en el ámbito nuclear estratégico de la Guerra Fría, como actores racionales que respondían mutuamente de manera calculada. 
En la década de los ochenta, sobre la base de los argumentos de Parsons (1951), Swidler (1986) afirmaría que las estrategias culturales impulsadas por los intereses, eran importantes condiciones de mediación en el comportamiento estatal, por ello definiría la cultura como "vehículos simbólicos de significado, que incluyen creencias, prácticas rituales, formas de arte y ceremonias, así como prácticas culturales informales como el lenguaje, el chisme, las historias y los rituales de la vida cotidiana" (p. 273). Por su lado, Gray (1981) sugeriría que los estilos nacionales distintivos, con raíces profundas dentro de un flujo particular de experiencia histórica, caracterizaban el desarrollo estratégico en las grandes potencias. Así, la cultura estratégica "proporcionaría el entorno dentro del cual se debatiría la estrategia y serviría como un determinante independiente de los patrones de política estratégica” (Gray, 1981, p. 35); como Snyder, Gray (1981) consideraba que la cultura estratégica sería una influencia semipermanente en la política de seguridad.

Por ende, la evolución en los estudios en cultura estratégica podría dividirse en tres generaciones. La primera generación, que surgió a principios de la década de los ochenta, se centraría principalmente en explicar por qué los soviéticos y los estadounidenses pensaban, aparentemente, de manera diferente sobre la estrategia nuclear. Basándose en los trabajos de Snyder (1977) sobre cultura estratégica y doctrina soviética de guerra nuclear limitada, autores como Gray (2013) argumentarían que estas diferencias fueron causadas por variaciones únicas en variables macroambientales, tales como una experiencia histórica, una cultura política y una geografía profundamente enraizada.

La segunda generación acerca de los estudios en cultura estratégica aparecería a mediados de la década de los ochenta; partiría de la premisa de que existía una gran diferencia entre lo que los líderes 'pensarían' o 'dirían' que están haciendo y aquellos motivos más profundos de lo que realmente 'harían'. En este contexto, la cultura estratégica se vería como una herramienta de hegemonía política en el ámbito de la toma de decisiones estratégicas que establecería "orientaciones ampliamente disponibles para la violencia y formas en que el Estado podría usar legítimamente la violencia contra enemigos putativos" (Klein, 1988, p. 136). Si bien la cultura estratégica sería instrumental (según la segunda generación), esta no provendría de la mente de las élites políticas y militares, sino que sería el producto de la experiencia histórica.

La tercera generación, que surgiría en la década de los noventa, tendería a ser a la vez más rigurosa y ecléctica en su conceptualización de variables ideacionales independientes, y más estrechamente enfocada en decisiones estratégicas particulares (como variables dependientes). Algunos usarían la cultura militar, alguna cultura 
político-militar y otras culturas organizacionales como la variable independiente, pero todos toman el edificio realista como objetivo, enfocándose en casos donde las nociones estructurales y materialistas de interés no podrían explicar una elección estratégica particular. Sus definiciones de cultura excluirían el comportamiento como un elemento, evitando así las trampas tautológicas de la primera generación (Johnston, 1995a).

Con base en todo lo anterior, existirían tres enfoques principales en el estudio de la correlación entre cultura y estrategia (Lantis y Howlett, 2016). El primer enfoque consideraría que la cultura es una explicación complementaria del comportamiento estratégico de un actor determinado; en este sentido, la cultura complementaría las teorías explicativas centradas en el interés nacional y la distribución del poder, considerándola como una variable que puede influir en el comportamiento sistémico internacional.

El segundo enfoque consideraría que la cultura es un concepto que puede explicar todos los comportamientos estratégicos; este enfoque se basaría en otras áreas de conocimiento, como la psicología política, con el fin de crear una teoría de la cultura estratégica que contribuya a un programa de investigación acumulativo. En consecuencia, la cultura estratégica sería una variable independiente que explica la toma de decisiones en materia de seguridad internacional, tanto o mejor que el propio neorrealismo o el institucionalismo neoliberal.

El tercer enfoque académico sostendría que los aspectos de la conducta humana solo se podrían entender al sumergirse en el interior de una cultura estratégica dada. Por lo tanto, algunos antropólogos y sociólogos consideran que la relación entre cultura y estrategia es extraordinariamente compleja, ya que consistiría en una combinación de expresiones discursivas (lo que se dice) y no discursivas (lo que no se dice). Razón por la cual sería imposible medir la influencia de la cultura en la estrategia.

\subsection{La teoría constructivista y la cultura estratégica}

En la década de los noventa, la influencia del constructivismo provocaría un renovado interés en los estudios relacionados con la cultura estratégica, a través de una nueva generación de obras académicas que reafirmarían la utilidad de las interpretaciones culturales. Según Lapid (1996),

la cultura y la identidad están escenificando un regreso dramático en la teoría y la práctica social a fines del siglo XX [...]. Los realistas políticos, que bajo el impacto de su movimiento Waltziano hacia el neorrealismo han marginado duramente la 
cultura y la identidad, están participando con cautela en esta tendencia. De manera similar, luego de un periodo de indiferencia hostil hacia las "explicaciones ideacionales", parece que el tiempo de las ideas ha vuelto a aparecer en la Economía Política Internacional. (p. 3)

Por ello, e inspirado por el auge del constructivismo, el renacimiento del interés por la cultura en los estudios de seguridad llevaría a los investigadores a sumergirse en la brecha entre las expectativas estructurales y las realidades de la política de seguridad, con modelos de comportamiento estatal culturalmente vinculados. Si bien el constructivismo abarcaría muchas posiciones teóricas, algunos académicos se interesarían en cómo las ideas, normas y factores culturales podrían ser tan influyentes (como los factores materiales), en la seguridad internacional. En consecuencia, Wendt (1992), uno de los primeros académicos de esta tradición, argumentaría que "las identidades e intereses del Estado se construyeron socialmente mediante la práctica informada" (p. 392). En este orden de ideas, para Hudson (1997) el constructivismo adoptaría el estudio de la cultura como un "sistema evolutivo de significado compartido que rige las percepciones, las comunicaciones y las acciones" (p. 29).

El programa de investigación constructivista ha dedicado especial atención a la formación de identidad, con conexiones con el proceso organizacional, la historia, la tradición y la cultura. Con base en lo anterior, han surgido destacados estudios académicos que han venido relacionando el constructivismo y la cultura estratégica, como el trabajo de Johnston (1995b), el cual sería considerado, hasta el presente, como una quintaesencia de la cultura estratégica influenciada por el constructivismo. Por su parte, otra rama en las investigaciones del constructivismo sobre la cultura estratégica se centraría en las culturas militares u organizacionales. En conjunto, estos estudios (Ebel et al., 1991; Kier, 1995; Legro, 1996; Rosen, 1995) sugerirían que la cultura organizacional podría ser un factor poderoso que influye en la elección estratégica.

\subsection{FUENTES DE CULTURA ESTRATÉgica}

Existirían varias fuentes de cultura estratégica, que abarcarían tanto factores materiales como simbólicos. En primer lugar, la geografía, el clima y los recursos parecieran ser elementos clave en el pensamiento estratégico a lo largo de la historia, y seguirían siendo fuentes importantes de la cultura estratégica en la actualidad. En efecto, las circunstancias geográficas podrían ser una clave para entender por qué algunos países adoptan políticas estratégicas particulares en lugar de otras. Por ejemplo, la proximidad geográfica a grandes potencias, como lo atestiguan los 
casos de Noruega y Finlandia, han llevado a que estos Estados adopten una política exterior neutral en algunos asuntos, debido a que su vecino inmediato durante la Guerra Fría fuera la Unión Soviética (Heikka, 2005). Por el contrario, el aislamiento relativo para países como Australia permitiría que este se enfocase en una política basada en la defensa continental. Además, si bien la mayoría de las fronteras territoriales se resuelven mediante negociación, otras se han forjado a través del conflicto y continuarían siendo materia de conflicto; algunos Estados tienen múltiples fronteras y podrían verse afectados por múltiples dilemas de seguridad; tales factores parecieran haber moldeado las orientaciones estratégicas de países como como Colombia, Israel o Corea del Sur. En efecto, Corea del Sur ha experimentado inseguridad en función de su proximidad geográfica con sus rivales de Corea del Norte y Japón. Garantizar el acceso a los recursos vitales también se consideraría fundamental para la estrategia, y este, así como otros factores parecieran ser especialmente importantes en las dinámicas geopolíticas y geoeconómicas en la actualidad.

En segundo lugar, la historia y la experiencia se constituirían como consideraciones importantes en la evolución de la cultura estratégica. Las teorías de las relaciones internacionales han identificado varias formas de categorizar a los Estados, que van desde débiles a fuertes, coloniales a poscoloniales, premodernos, modernos y posmodernos, entre otros. Esto plantearía la posibilidad de que diferentes tipos de Estados pudiesen enfrentar diferentes problemas estratégicos, de acuerdo con su longevidad. Por ejemplo, para aquellos Estados recientemente formados, las dificultades de la construcción de nación podrían generar inseguridades y, por lo tanto, ayudar a formar identidades culturales estratégicas; en contraste, para aquellos Estados más antiguos, una dilatada existencia podría impulsar la consideración de aquellos factores que contribuyen al ascenso y caída de grandes poderes o civilizaciones y, por ende, dar forma a sus políticas.

Otra fuente de cultura estratégica podría ser la naturaleza de la estructura política de Estado, así como la de sus organizaciones de defensa. Por ejemplo, algunos Estados adoptarían un estilo de gobierno occidental, basado en regímenes democrático-liberales, mientras que otros no. Asimismo, algunos se considerarían democracias maduras, mientras que otros estarían experimentando transformaciones democráticas. En lo que respecta a estos últimos, podrían existir variables culturales como las lealtades tribales, religiosas o étnicas, que operarían dentro y fuera de los límites territoriales, lo que determinaría, en consecuencia, el ritmo y la profundidad de la consolidación democrática, como sucedería con algunos Estados africanos. De forma similar, algunos académicos (Adamsky, 2010; Scobell, 2014; Castro, 2014) considerarían que las organizaciones de defensa, las doctrinas militares y las relaciones cívico-militares serían críticas para las culturas estratégicas de los Estados. 
En cuarto lugar, los mitos y símbolos podrían actuar como factores estabilizadores o desestabilizadores en la evolución de las identidades culturales estratégicas. Calvert (2004) sostiene que los mitos podrían referirse como "un conjunto de creencias que expresarían los valores políticos fundamentales (inconscientes o asumidos) de una sociedad; es decir, una dramática expresión de ideología" (p. 31). Con respecto a los símbolos, Poore (2004) sugiere que estos actuarían como objetos socialmente reconocidos que proporcionarían a una comunidad cultural puntos de referencia estables para el pensamiento y la acción estratégica. Asimismo, las narrativas históricas también impactarían las concepciones de los roles estatales; según Breuning (1997), los "roles" serían una extensión de las axiomáticas creencias culturales ${ }^{35}$ con respecto a la relación del Estado con el sistema internacional (actores versus sujeto); la naturaleza del sistema internacional (universalista contra particularista); y la comprensión de las reglas de comportamiento (intención versus resultados). Estos roles se manifestarían luego en diferentes comportamientos de política exterior y de seguridad, ya que los valores culturales que darían forma a una sociedad, limitarían las opciones de política exterior de sus líderes. Por ejemplo, una historia heroica sería un recuerdo de un momento en que el Estado o la organización sociopolítica era un significativo o poderoso actor en las dinámicas globales o regionales; tal memoria podría conducir a los tomadores de decisiones a sostener la creencia axiomática de que podrían hacer una diferencia en el entorno internacional. En contraste, la ausencia de tal historia podría llevar a la creencia de que el destino del Estado estaría sujeto a fuerzas que escapan al control de quienes toman las decisiones. En resumen, una historia heroica conduciría a una orientación del actor, mientras que la ausencia de dicha historia conduciría a una orientación del sujeto.

\subsubsection{Guardianes de la CUltura estratégica}

Un tema de los estudios culturales estratégicos contemporáneos ha sido el esfuerzo por identificar a los 'guardianes' de la cultura estratégica. Estos estudios también aludirían a las sutilezas asociadas con la determinación de si los individuos o las élites tendrían mayor influencia en los resultados estratégicos. Si bien ciertas investigaciones en el pasado (Wilson, 2000) tendían a describir las culturas políticas y estratégicas como propiedades exclusivas de los Estados, las élites (legisladores y generadores de opinión de alto nivel) podrían constituirse como los principales proveedores de una narrativa histórica común y, por tanto, como los guardianes

35 Las creencias podrían denominarse 'axiomáticas' cuando constituyen las premisas básicas que organizan todos los demás conocimientos. 
de la cultura estratégica de un Estado. Si bien la cultura estratégica podría tener profundas raíces en la sociedad, trabajos más recientes sobre el discurso político (Swidler, 1986; Cruz, 2000; Hymans, 2006) sugerirían que la cultura estratégica se caracterizaría mejor como una realidad negociada entre las élites. En efecto, Hymans (2006) sostiene que la identidad sería tanto subjetiva como intersubjetiva, y que los líderes a menudo adoptarían sus propias concepciones específicas de identidad nacional en un mercado competitivo de ideas, mientras que Cruz (2000) afirma que las élites tendrían más libertad de lo que los académicos generalmente permitirían, ya que "pueden reformular una agenda particular como la más apropiada para una realidad colectiva dada o redefinir los límites de lo posible, tanto descriptiva como prescriptivamente" (p. 278).

Finalmente, los constructivistas posestructurales (Milliken, 1999; Miskimmon, 2004; Mattern, 2005) también observarían cómo las élites podrían ser tanto guardianes como usuarios estratégicos de la cultura, por manipular los marcos culturales como una forma de hacer una excepción a los límites estructurales intersubjetivos. Por su parte, Kupchan (1994) ha argumentado que los fundamentos de la cultura estratégica son sociales; basada en imágenes y símbolos, la cultura estratégica se referiría a "imágenes que dan forma a la forma en que la nación como entidad colectiva define su bienestar y concepción de su seguridad” (p. 21). En consecuencia, un amplio apoyo para una narrativa histórica previa podría condicionar la política de seguridad, así como el potencial para un cambio cultural estratégico. En este sentido, los responsables de la GE podrían ser los 'guardianes' de la cultura y el pensamiento estratégico nacional (conformados por la élite académica, política, militar, económica y social), responsables del liderazgo nacional, la preservación de los valores y creencias ${ }^{36}$ de la nación, así como de la visión estratégica de largo aliento del Estado en procura del logro de los intereses nacionales.

\section{Conclusiones}

Cualquier estrategia, grandiosa o insignificante, implicaría tanto un objetivo como los medios necesarios para alcanzarlo. En este orden de ideas, en la mayoría de los casos, los Estados buscarían mantener su independencia, extender su influencia y, en ocasiones, ampliar su dominio. Para lograrlo, las herramientas clásicas a disposición de los Estados han sido generalmente las fuerzas armadas, la riqueza y sus

36 Los valores y creencias de la nación, encarnados en los intereses nacionales, representarían la base legal, filosófica y moral para la supervivencia del Estado. 
aliados (Howard, 2001). Las capacidades económicas son necesarias para mantener las fuerzas armadas, pero las fuerzas armadas podrían usarse para adquirir riqueza, ya sea por la adquisición y explotación de la tierra y sus recursos minerales o por la extensión y protección del comercio. La riqueza también puede atraer y retener a los aliados, para compensar cualquier déficit en las propias fuerzas armadas. Hasta el final del siglo XVIII, las relaciones internacionales consistían, en gran medida, en la interacción de estos tres elementos. Luego, la Revolución francesa introduciría un cuarto elemento: la opinión pública; el impacto inmediato de la opinión pública sería doméstico, como un multiplicador de la fuerza, tal como lo demostrarían los franceses en las guerras napoleónicas, ya que podría proporcionar tanto mano de obra como riqueza en cantidades sin precedentes, como sería testigo el siglo XIX. Pero a medida que aumentaba el grado de participación popular en el gobierno, se hacía más importante ese apoyo para la provisión no solo de mano de obra, sino también de riqueza en forma de préstamos e ingresos fiscales.

Posteriormente, en el siglo xx, a medida que las comunicaciones globales se desarrollaban desde los medios impresos a la radio, y luego al internet, estas también se convertirían en una significativa arma ofensiva. La movilización de la opinión pública en el ámbito nacional, la persuasión de la opinión en Estados neutrales y el socavamiento de la legitimidad del gobierno adversario a través de la propaganda, se convertirían en herramientas de la gran estrategia de los Estados, como lo eran el mantenimiento y el despliegue de las fuerzas armadas, la preservación de una economía saludable y la preservación de alianzas. Hasta el punto de que durante la Guerra Fría serían, posiblemente, la herramienta más importante y tal vez la más efectiva de todas (Serrano, 2018).

La GE no sería una simple estrategia; si bien los dos términos a menudo se confunden, serían conceptualmente diferentes. La GE tendría un alcance más amplio e integrador, que abarcaría el desarrollo de los recursos económicos, demográficos y sociales de una sociedad, la asignación de estos recursos y la aplicación unificada de los diversos instrumentos del poder nacional. En una era de austeridad, con más demandas que nunca por recursos escasos, el hecho de relacionar con claridad los fines con los medios se ha convertido en un imperativo estratégico. En un mundo cada vez más globalizado, muchos Estados se preocuparían no solo por la forma más efectiva, sino también por la forma más eficiente de satisfacer sus objetivos. En este sentido, la GE se presentaría como un enfoque conceptual que podría ayudar en una mejor asignación de recursos escasos a problemas difíciles, siempre y cuando los encargados del diseño de las políticas públicas sepan hacia dónde deberían dirigirse las más altas aspiraciones estratégicas del Estado. Según 
Layton (2012), una GE sería exigente en sus requisitos, al obligar a los responsables de la toma de decisiones a identificar claramente los fines que buscan.

Por el contrario, una GE podría llegar a ser una herramienta de política inadecuada, si no existe una cultura y pensamiento estratégico anticipatoria. La cultura se definiría en términos cognitivos, porque sería a través de la mediación de los mecanismos cognitivos que la herencia común de una sociedad influiría en el contenido y la estructura de los procesos de toma de decisiones. Sackmann (1991) ha definido la cultura en las organizaciones como "una construcción social de reglas que guían las percepciones y el pensamiento". Además, estas construcciones "surgen en un proceso de interacción social que está principalmente orientado a la resolución de problemas. Con el tiempo se estaría creando un cuerpo de conocimiento cultural que se transmite a otras generaciones" (p. 22).

En otras palabras, la génesis de la cultura estaría en aquellas prácticas que desarrollarían los individuos dentro de una organización cuando enfrentan problemas que necesitarían ser resueltos; una vez establecidas, estas prácticas se transmitirían a los nuevos miembros de la organización. De hecho, los individuos podrían ser seleccionados sobre la base de su percibida compatibilidad con las prácticas de la organización (Sackmann, 1991). Si bien los ciudadanos no serían generalmente 'seleccionados' como ciudadanos de un Estado, se podría argumentar que la selección en posiciones de liderazgo, responsabilidad y poder favorecería a aquellas personas que posean ciertos rasgos y cualidades valiosas. Se asumiría que los valores socioculturales serían creencias axiomáticas que los miembros de una sociedad tendrían en común, incluso si las opiniones que derivan de estas creencias llegasen a variar. Una clave para tales axiomas se podría encontrar en los mensajes y significados integrados en la historia nacional, ya que lo que contaría no sería tanto los eventos literales como las "lecciones aprendidas" y la "moraleja de la historia" (Breuning, 1997).

En efecto, los significados de un tipo de desarrollo de identidad o de alteración de identidad, probablemente se encontrarían en eventos que marcaron puntos de inflexión en la historia del Estado: por ejemplo, eventos que rodearon la fundación del Estado o que impactaron al sistema y a los líderes que, en consecuencia, realizaron actos heroicos en respuesta a o precipitando tales eventos. El sentido colectivo de identidad que se supondría es resultado de tales eventos, se enseñaría a las nuevas generaciones con el objeto de percibir su Estado en términos de ello. Esta concepción o identidad de rol nacional afectaría el comportamiento de la política de seguridad y defensa de dos maneras: tendría un impacto a través de los marcos institucionales que son negociados por los fundadores y alterados en puntos de 
inflexión posteriores, y daría forma a los parámetros de las visiones concebibles de los futuros deseados.

Por el contrario, bajo un enfoque reactivo de la cultura y el pensamiento estratégico de una sociedad, las políticas de un Estado cambiarían y evolucionarían según lo requiera la situación, en lugar de ser impulsadas por una GE, que no podría llegar a evolucionar tan rápido como el entorno internacional. Empero, la dificultad con un Estado reactivo, como el colombiano, es que reacciona ante los eventos y las acciones de otros; al ser reactivo, un Estado no propone y, por lo tanto, deberá aceptar los límites determinados en otra parte, de este modo haría parte del proyecto estratégico de otro Estado, que establecería la gran agenda estratégica y determinaría el marco de los debates, consciente de sus propios objetivos y capacidades. En consecuencia, el Estado reactivo solo podría estar listo para actuar según lo dicten las circunstancias y adoptaría un enfoque de gestión de riesgos que guíe las acciones para mitigar el impacto de calamidades inevitables. Las alternativas del reactivismo y la gestión de riesgos estarían centradas en los medios, mientras que la GE en los fines.

\section{Referencias}

Adamsky, D. (2010). Culture of Military Innovation: The Impact of Cultural Factors on the Revolution in Military Affairs in Russia, the US, and Israel. Palo Alto: Stanford University Press.

Ailleret, C. (1950). Le Art de la Guerre et la Technique. París: Charles-Lavauzelle y Cia.

Almond, G. y Verba, S. (1965). The Civic Culture: Political Attitudes and Democracy in Five Nations. Boston: Little, Brown \& Co.

Álvarez, C. (2017a). Ocupación de los espacios vacíos: una condición sine qua non para la seguridad multidimensional en Colombia. En C. Álvarez (ed.), Escenarios y desafíos de la seguridad multidimensional en Colombia (pp. 307-386). Bogotá: Ediciones Esdegue.

Álvarez, C. (2017b). Geopolítica de la cultura: el papel de los medios de comunicación en la reconfiguración del sistema internacional. Revista Fuerzas Armadas, XC (239), 41-48.

Álvarez, C., Santafé, G. y Urbano, O. (2017). Metamorphosis Bellum: ¿Mutando a guerras de quinta generación? En C. Álvarez (ed.), Escenarios y desafios de la seguridad multidimensional en Colombia (pp. 145-248). Bogotá: Ediciones Esdegue.

Álvarez, C. (2018). La geopolítica de las emociones. Revista Fuerzas Armadas, XCI, (243), 6-14.

Álvarez, C. y Rodríguez, C. (2018). Criminal Ecosystems: Habitats for Convergence and Deviated Globalization. Revista Cientifica José María Córdova, 16 (24), 5-42.

André, B. (1964). Dissuasion et Stratégie. París: Armand Colin.

Aranda, M. (1957). El arte militar. Madrid: Ediciones Pegaso.

Arquilla, J. y Nomura, R. (2015). Three Wars of Ideas about the Idea of War. Comparative Strategy, $34(2), 185-201$. 
Aron, R. (2004). Paix et Guerre entre les Nations. París: Calmann-Lévy.

Baylis, J. y Wirtz, J. (2016). Strategy in the Contemporary World: Strategy After 9/11. En J. Baylis, J. Wirtz y C. Gray (eds.), Strategy in the Contemporary World (pp. 1-17). Oxford: Oxford University Press.

Beaufre, A. (1965). An introduction to strategy. New York: F.A. Praeger.

Beaufre, A. (1978). Estrategia de la acción. Buenos Aires: Pleamar.

Betts, R. (1997). Should Strategic Studies Survive. World Politics, 50 (1), 7-33.

Betts, R. (2007). The Enemies of Intelligence: Knowledge and Power in American National Security. Nueva York: Columbia University Press.

Bernhardi, F. (1916). Alemania y la próxima guerra. Barcelona: Ronda Universidad.

Boot, M. (2013). Invisible Armies: An Epic History of Guerrilla Warfare from Ancient Times to the Present. Nueva York: Liveright.

Booth, K. (1981). Strategy and Ethnocentrism. Nueva York: Holmes and Meier.

Booth, K. y Trood, R. (1999). Strategic Culture in the Asia Pacific. Nueva York: Macmillan.

Bouthoul, G. (1970). Traité de Polémologie: Sociologie des Guerres. París: Payot.

Brams, S. y Kilgour, D. (1988). Game Theory and National Security. Nueva York: Basıl Blackwell.

Brands, H. (2014). What Good is Grand Strategy?: Power and Purpose in American Statecraft form Harry S. Truman to George W. Bush. Ithaca: Cornell University Press.

Breuning, M. (1997). Culture, History, Role: Belgian and Dutch Axioms and Foreign Assistance Policy. En V. Hudson (ed.), Culture and Foreign Policy (pp. 99-123). Boulder: Lynn Rienner Publishers.

Brodie, B. (1944). A Guide to Naval Strategy. Princeton: Princeton University Press.

Brodie, B. (1959). Strategy in the Missile Age. Princeton: Princeton University Press.

Brodie, B. (1973). War and Politics. Londres: Cassell.

Brzezinski, Z. (1988). El juego estratégico: la conducción de la contienda entre los Estados Unidos y la Unión Soviética. Buenos Aires: Planeta.

Brzezinski, Z. (1997). The Grand Chessboard: American Primacy and Its Geostrategic Imperatives. Nueva York: Basic Books.

Brzezinski, Z. (1998). El gran tablero mundial: la supremacía estadounidense y sus imperativos estratégicos. Barcelona: Paidós.

Buzán, B. y Waever, O. (2003). Regions and Powers: The Structure of International Security. Nueva York: Cambridge University Press.

Calvert, J. (2004). The Mythic Foundations of Radical Islam. Orbis, 48, 29-41.

Castex, R. (1994). Strategic Theories. Annapolis: us Naval Institute Press.

Castro, R. (2014). Philippine Strategic Culture: Continuity in the Face of Changing Regional Dynamics. Contemporary Security Policy, 35 (2), 249-269.

Celelier, P. (1979). Geopolitica y geoestrategia. Buenos Aires: Pleamar.

Centro de Doctrina del Ejército. (2016). Doctrina Damasco: MFE 1-01. Bogotá: Ejercito Nacional de Colombia 
Chaliand, G. (1982). Guerrilla Strategies: An Historical Anthology from the Long March to Afghanistan. Los Ángeles: University of California Press.

Churchill, W. (2002). The Second World War. Londres: Random House.

Clausewitz, C. von (1989). On war. Princeton: Princeton University Press.

Cohen, S. (2009). Geopolitics: The Geography of International Relations. Lanham: Rowman y Littlefield Publishers.

Collins, J. (1973). Grand strategy: Principles and Practices. Annapolis: Naval Institute Press.

Collis, D. y Rukstad, M. (2008). Can You Say What Your Stratagy Is? Harvard Buisness Review, 86(4), 82-90.

Corbett, J. (1909). Strategical Terms and Definitions Used in Lectures on Naval History (Nmm CBT/6/1516, Corbett Papers). Londres: National Maritime Museum.

Corbett, J. (1911). Principles of Maritime Strategy. Nueva York: Dover Publications (reed. 2004).

Corvisier, A. (1994). A Dictionary of Military History and the Art of War. Oxford: Blackwell Reference.

Craig, G. (1955). The Politics of the Prussian Army 1640-1945. Toronto: Clarendon Press.

Creveld, M. (1989). Technology and War from 2000 BC to the Present. Nueva York: The Free Press.

Creveld, M. (1991). The Transformation of War. Nueva York: The Free Press.

Crozier, B. (1960). The Rebels: A Study of Post-War Insurrections. Londres: Chatto and Windus.

Cruz, C. (2000). Identity and Persuasion: How Nations Remember their Pasts and Make their Futures. World Politics, 52 (3), 275-312.

Cummings, S. (1995). Pericles of Athens: Drawing from the Essence of Strategic Leadership. Business Horizons, 38, (Issue 1), 22-37.

Defense Council. (2004). British Maritime Doctrine BR 1806 (3. ${ }^{\mathrm{a}}$ ed.). Londres: Defense Council.

Deibel, T. (2007). Foreign Affairs Strategy: Logic for American Statecraft. Cambridge: Cambridge University Press.

De Gaulle, C. (2015). Le Fil de l'Épée. París: Tempus Perrin.

Delbrück, H. (1985). History of the Art of War within the Framework of Political History: The Modern Era. Londres: Praeger.

Dennis, G. (trad.) (1984). Maurice's Stratēgikon: Handbook of Byzantine Military Strategy. Filadelfia: University of Pennsylvania Press.

Dennis, G. (trad.) (2010). The Taktika of Leo VI. Washington: Dumbarton Oaks.

Donnelly, J. (2005). Realism. En S. Burchill, A. Linklater, R. Devetak, J. Donnelly, M. Paterson, C. Reus-Smit, C. y J. True (eds.), Theories of International Relations (3. ${ }^{\text {a ed. }) . ~ N u e v a ~ Y o r k: ~ P a l g r a v e ~}$ Macmillan.

Douhet, G. (1921). Il Dominio Dell'aria. Roma: C. De Alberti.

Douhet, G. (1955). Il Dominio dell'Aria. Roma: Rivista Aeronautica.

Dueck, C. (2015). The Obama Doctrine: American Grand Strategy Today. Oxford: Oxford University Press.

Duffield, J. (1988). World Power Forsaken: Political Culture, International Institutions and German Security Policy after Unification. Stanford: Stanford University Press. 
Duffield, J. (1999). Political Culture and State Behaviour. En International Organization, 53(4), 765-804.

Dufort, P. (2017). La influencia de la comprensión cambiante del poder sobre la estrategia: un ensayo genealógico. Revista Cientifica General José María Córdova, 15(19), 29-81. https://doi. org/10.21830/19006586.83

Earle, E. (1943). Makers of Modern Strategy: Military Thought from Machiavelli to Hitler. Princeton: Princeton University Press.

Ebel, R., Taras, R. y Cochrane, J. (1991). Political Culture and Foreign Policy in Latin America: Case Studies from the Circum-Caribbean. Albany: State University of New York.

Echevarría, A. (2002). Clausewitz's Center of Gravity: Changing oir Warfighting Doctrine. Washington: U. S. Army War College.

Echevarría, A. (2014). Reconsidering the American Way of War. Washington: Georgetown University Press.

Edelstein, D. y Krebs, R. (2015). Delusions of Grand Strategy: The Problem with Washington's Planning Obsession. Foreign Affairs, 94 (6), 109-116.

Eisenhower, D. (1997). Crusade in Europe. Washington: jнu Press.

Fairgriebe, J. (1917). Geography and World Power. Middletown: Forgotten Books (réed. 2012).

Falls, C. (1961). The Art of War. Oxford: Oxford University Press.

Feaver, P. (2009). What is Grand Strategy and Why Do We Need It? Foreign Policy, 316, 14-32.

Fernandez-Osorio, A., Cufiño-Gutierrez, F., Gomez-Diaz, C., \& Tovar-Cabrera, G. (2018). Dynamics of State modernization in Colombia: the virtuous cycle of military transformation. Democracy \& Security, https://doi.org/10.1080/17419166.2018.1517332

Fernandez-Osorio, A., Latorre Rojas, E., \& Mayorga Zarta, N. (2018). The 2018 Colombian Military Academy dataset: A sociological study of population. Revista Cientifica General José María Córdova, 16(23), 147-162. https://doi.org/10.21830/19006586.345

Foch, F. (1920). The Principles of War. Londres: Henry Hold and Company.

Fontaine, A. (1983). Histoire de la Guerre Froide: De la Guerre de Corée à la Crise des Alliances 19501971. París: Fayard.

Foster, G. (1985). Missing and Wanted. Strategic Review, 13, 13-15.

Freedman, L. (1981). The Evolution of Nuclear Strategy. Londres: Palgrave.

Freedman, L. (2013). Strategy: A History. Oxford: Oxford University Press.

Friedberg, A. (2000). In the Shadow of the Garrison State: America's Anti-Statism and Its Cold War Grand Strategy. Princeton: Princeton University Press.

Friedman, G. (2009). The Next 100 Years: A Forecast for the 21st Century. Nueva York: Doubleday.

Fuerzas Militares de Colombia. (2005). Manual de Estado Mayor y Mando Conjunto para las FF. MM. Bogota: Comando General de las FF. MM, 3-25

Fukuyama, F. (1992). End of History and the Last Man. Nueva York: Macmillan.

Fuller, J. (1923). The Reformation of War. Londres: Hutchinson and Co.

Gaddis, J. L. (2018). On Grand Strategy. Nueva York: Penguin Books.

Gallois, P. y Dupuy, R. (2000). Géopolitique: les Voies de la Puissance. París: L’Age d'homme.

Garthoff, R. (1966). Soviet Military Policy: A Historical Analysis. Nueva York: Praeger. 
Gat, A. (1989). The Origins of Military Thought from the Enlightenment to Clausewitz. Oxford: Clarendon Press.

Geertz, C. (1973). The Interpretation of Cultures. New York: Basic Books.

Giap, V. N. (1970). Military Art of People's War. Boston: Monthly Review Press.

Glantz, D. (1991). La Conducción Soviética de la Maniobra Táctica. Madrid: Editorial Impresa.

Glenn, J.; Howlett, D. y Poore, S. (2004). Neorealism versus Strategic Culture. Londres: Ashgate.

Glenn, J. (2009). Realism versus Strategic Culture: Competition and Collaboration? International Studies Review, 11(3), 523-551.

Goerlitz, W. (1953). German General Staff. Nueva York: Praeger.

Gray, C. (1981). National Style in Strategy: The American Example. International Security, 6 (2), 35-57.

Gray, C. (1982). Strategic Studies: A Critical Assessment. Londres: Aldwych Press.

Gray, C. (1999). Modern Strategy. Oxford: Oxford University Press.

Gray, C. (2013). Perspectives on Strategy. Oxford: Oxford University Press.

Gray, C. y Sloan, G. (1999). Geopolitics, Geography and Strategy. Nueva York: Routledge.

Hackett, J. (1979). The Third World War. Nueva York: Macmillan.

Hanson, V. (2013). The Savior Generals: How Five Great Commanders Saved Wars That Were Lost: from Ancient Greece to Iraq. Nueva York: Bloomsbury Press.

Haushofer, K. (1975). Poder y espacio. Buenos Aires: Pleamar.

Heikka, H. (2005). Republican Realism: Finnish Strategic Culture in Historical Perspective. Cooperation and Conflict, 40 (1), 91-119.

Herberg-Rothe, A. (2014). Clausewitz's Concept of Strategy: Balancing Purpose, Aims and Means. Journal of Strategic Studies, 37 (6-7), 903-925.

Heuser, B. (2010). The Evolution of Strategy. Cambridge: Cambridge University Press.

Hill, C. (2010). Grand Strategies: Literature, Statecraft and World Order. New Haven: Yale University Press.

Hobbes, T. (1651). Leviathan. Londres: Penguin (reed. 1985).

Hoffman, S. (1987). Janus and Minerva: Essays in the Theory and Practice of International Politics. Boulder: Westview Press.

Holcomb, J. (2004). Managing Strategic Risk. Some Basic Concepts and Approaches in the Study of International Politics, 119-132.

Hooker, R. (2014). The Grand Strategy of the United States. Washington: National Defense University Press.

Howard, M. (1979). The Forgotten Dimensions of Strategy. Foreign Affairs, 57 (5), 934-979.

Howard, M. (1983). The Causes of War. Londres: Counterpoint.

Howard, M. (1993). The Mediterranean Strategy in the Second World War. Londres: Greenhill Press.

Howard, M. (2001). Grand Strategy in the Twentieth Century. Defence Studies, 1 (1), 1-10.

Howard, M. (2009). War in European History. Oxford: Oxford University Press.

Hudson, V. (1997). Culture and Foreign Policy. Boulder: Lynne Rienner. 
Hughes, D. (1993). Moltke on the Art of War: Selected Writings. Toronto: Random House.

Huntington, S. (1997). The Clash of Civilizations and the Remaking of World Order. Londres: Penguin Books.

Hymans, J. (2006). The Psychology of Nuclear Proliferation: Identity, Emotions, and Foreign Policy. Cambridge: Cambridge University Press.

Jablonsky, D. (1993). Why is Strategy Difficult? En G. Guertner (ed.), The Search For Strategy (pp. 69-78). Westport: Greenwood Press.

Johnson, J., Kartchner, K. y Larsen, A. (2009). Strategic Culture and Weapons of Mass Destruction: Culturally Based Insights into Comparative National Security Policymaking. Londres: Palgrave Macmillan.

Johnson, L. (2003). Preface to a Theory of Strategic Intelligence. International Journal of Intelligence and Counter Intelligence, 16 (4), 638-663.

Johnston, A. (1995a). Thinking about Strategic Culture. International Security, 19 (4), 32-64.

Johnston, A. (1995b). Cultural Realism: Strategic Culture and Grand Strategy in Chinese History. Princeton: Princeton University Press.

Joint Chiefs of Staff. (2002). Joint Doctrine for Campaign, Joint Pub 5-00.1. Washington: Joint Chiefs of Staff.

Joint Chiefs of Staff. (2018). Joint Doctrine Note 1-18, Strategy., Washington: Joint Chiefs of Staff.

Jomini, A. H. (1977). The Art of War. Westpoint: us Military Academy.

Kagan, D. (1991). Pericles of Athens and the Birth of Democracy. Nueva York: Free Press.

Kahn, H. y Wiener, A. J. (1969). The Year 2000. Nueva York: Macmillan.

Kahn, H. (1989). On Escalation. In Us Nuclear Strategy. Londres: Palgrave Macmillan.

Kassab, H. S. (2018). Grand Strategies of Weak States and Great Powers. Nueva York: Palgrave Macmillan.

Katzenstein, P. (1996). The Culture of National Security: Norms and Identity in World Politics. Nueva York: Columbia University Press.

Keegan, J. (1971). Barbarossa: Invasion of Russia. Nueva York: Ballantine Books.

Kennedy, P. (1987). The Rise and Fall of the Great Powers. Nueva York: Random

Kennedy, P. (1991). Grand Strategies in War and Peace. New Haven: Yale University Press.

Kent, S. (1966). Strategic Intelligence for American World Policy. Princeton: Princeton University Press.

Keynes, J. M. (1936). The General Theory of Employment, Interest and Money. Nueva York: Bn Publishing (réed. 2017).

Kier, E. (1995). Culture and Military Doctrine: France Between Wars. International Security, 19 (14), 65-94.

Kindelán, A. (1945). La próxima guerra. Madrid: Ediciones Ares.

Kissinger, H. (1984). Nuclear Weapons and Foreign Policy. Nueva York: Westview Press.

Kjellén, R. (1916). Staten Som Liffform. Estocolmo: Hugo Geber.

Klein, B. (1988). Hegemony and Strategic Culture: American Power Projection and Alliance Defence Politics. Review of International Studies, 14 (2), 128-145.

Klein, B. (1991). A Theory of Strategic Culture. Comparative Strategy, 10 (1), 3-23. 
Klein, B. (1994). Strategic Studies and World Order: The Global Politics of Deterrence. Cambridge: Cambridge University Press.

Kohout, J. (1995). Alternative Grand Strategy Options for the United States. Comparative Strategy, 14 (4), 361-420.

Kolko, G. (1968). The Politics of War: The World and United States Foreign Policy 1943-1945. Nueva York: Random House.

Kornberger, M. (2013). Clausewitz: On Strategy. Business History, 55 (7), 1058-1073.

Krasner, S. (2010). An Orienting Principle for Foreign Policy. Policy Review, 163, 2-21.

Kupchan, C. (1994). The Case for Collective Security. Ann Arbor: University of Michigan Press.

Lacoste, Y. (1976). La Géographie, Ça sert, D’abord, à Faire la Guerre. París: Maspero.

Lacouture, J. (1966). Vietnam: Between Two Truces. Nueva York: Random House.

Lantis, J. (2002). Strategic Culture and National Security Policy. International Studies Review, 4 (3), 87-113.

Lantis, J. (2005). American Strategic Culture and Transatlantic Security Ties. Controversies in Politics, 24 (1), 46-55.

Lantis, J. (2009). Strategic Culture and Tailored Deterrence: Bridging the Gap Between Theory and Practice. Contemporary Security Policy, 30 (3), 467-485.

Lantis, J. y Howlett, D. (2016). Strategic Culture. J. Baylis, J. Wirtz y C. Gray (eds.), Strategy in the Contemporary World (pp. 85-120). Oxford: Oxford University Press.

Lantis, J. (2014). Strategic Cultures and Security Policies in the Asia Pacific. Contemporary Security Policy, 35 (2), 166-186.

Lapid, Y. (1996). Culture's Ship: Returns and Departures in International Relations Theory. En Y. Lapid y F. Kratochwil (eds.), The Return of Culture and Identity in IR Theory (pp. 3-20). Boulder: Lynne Rienner.

Lawrence, T. E. (1935). Seven Pillars of Wisdom. Londres: Wordsworth Editions (reed. 1997).

Layton, P. (2012). The Idea of Grand Strategy. The RUSI Journal, 157 (4), 56-61

Legro, J. (1996). Culture and Preferences in the International Cooperation Two-Step. American Political Science Review, 90 (1), 118-137.

Lempert, R., Popper, S. y Bankes, S. (2003). Shaping the Next One Hundred Years: New Methods for Quantitative Long-term Policy Analysis. Santa Monica: RAND Corporation.

Liang, Q. y Xiangsui, W. (2002). Unrestricted Warfare: China's Master Plan to Destroy America. Panama City: Pan American Publishing Company.

Liddell, B. H. (1929). The Decisive Wars of History: A Study in Strategy. Londres: G Bell y Sons.

Liddell, B. H. (1932). The British Way in Warfare. Londres: Faber and Faber.

Liddell, B. H. (1954). The Strategy of Indirect Approach. Londres: Faber and Faber.

Liddell, B. H. (1970). History of the Second World War. Nueva York: GP Putnam's Sons.

Lind, W., Nightengale, K., Schmitt, J., Sutton, J. y Wilson, G. (1989). The Changing Face of War: Into the Fourth Generation Warfare. Marine Corps Gazette, 73 (10), 22-26.

Ludendorff, E. (1935). Der totale Krieg. Múnich: Ludendorffs Verlag.

Luttwak, E. (2001). Strategy: The Logic of War and Peace. Cambridge: Harvard University Press. 
Luttwak, E. (2009). The Grand Strategy of the Byzantine Empire. Cambridge: Harvard University Press. Lykke Jr., A. (1989). Defining Military Strategy. Military Technology, 69(5), 2-8.

Lykke Jr., A. (2001). Toward an Understanding of Military Strategy. US Army War College Guide to Strategy, (February), 179-185.

Lynch, R. (2006). Corporate Strategy. Essex: Pearson.

Machiavelli, N. (1531). The Prince. Indianapolis: Hackett Publishing Company (reed. 1995)

MacKenzie, D. (1990). Inventing Accuracy: An Historical Sociology of Nuclear missile Guidance. Cambridge: MIT University Press.

Mackinder, H. (1904). The Geographical Pivot of History. The Geographical Journal, 23 (4).

Mackinder, H. (1919). Democratic Ideals and Reality. Middletown: Forgotten Books (réed. 2012).

Mahan, A.T. (1894). The Influence of Sea Power Upon History 1660-1783. Boston: Little, Brown y Co.

Mahnken, T. (2016). Strategic Theory. En J. Baylis, J. Wirtz y C. Gray (eds.), Strategy in the Contemporary World (pp. 52-66). Oxford: Oxford University Press.

Martel, W. (2015). Grand Strategy in Theory and Practice: The Need for an Effective American Foreign Policy. Cambridge: Cambridge University Press.

Marx, K. (1887). Capital. Moscú: Progress Publishers (réed. 1999).

Mattern, J. (2005). Ordering International Politics: Identity, Crisis, and Representational Force, Londres: Routledge.

McNamara, R. (1968). The Essence of Security. Nueva York: Harper and Row.

Mead, E. (1968). Creadores de la estrategia moderna: el pensamiento militar desde Maquiavelo a Hitler. Buenos Aires: Círculo Militar.

Metz, S. (2008). Iraq and the Evolution of American Strategy. Washington: Potomac Books.

Milevski, L. (2014). Grand Strategy and Operational Art: Companion Concepts and Their Implications for Strategy. Comparative Strategy, 33 (4), 342-353.

Milliken, J. (1999). The Study of Discourse in International Relations. European Journal of International Relations, 5 (2), 225-254.

Milward, A. (1979). War, Economy and Society 1939-1945. Berkeley: University of California Press.

Minh, H. C. (1984). On Revolution: Selected Writings: 1920-66. Boulder: Westview Press.

Mintzberg, H. (2007). Tracking Strategies: Toward a General Theory. Oxford: Oxford University Press.

Miskimmon, A. (2004). Continuity in the Face of Upheavel: British Strategic Culture and the Impact of the Blair Government. European Security, 13 (3), 273-299.

Montesquieu, C. (1752). The Spirit of Laws. Londres: Pantianos Classics (reed. 2011)

Moss, R. (1972). Urban Guerrilla Warfare. Washington: International Institute for Strategic Studies.

Murray, W., Knox, M. y. Bernstein, A. H. (1994). The Making of Strategy: Rulers, States, and War. Cambridge: Cambridge University Press.

Narizny, K. (2007). The Political Economy of Grand Strategy. Ithaca: Cornell University Press.

Neibuhr, R. (1932). Moral Man and Immoral Society: A Study in Ethics and Politics. Nueva York: Charles Scribner's Sons.

Osgood, R. E. (1957). Limited War. Boston: University of Chicago Press.

Parker, G. (1998). The Grand Strategy of Philip II. New Haven: Yale University Press. 
Parker, G. (2010). Historia de la guerra. Madrid: Akal.

Parsons, T. (1951). The Social System. Londres: Routledge.

Petroski, H. (1982). To Engineer is Human: The Role of Failure in Successful Design. Nueva York: Random House.

Poore, S. (2004). Strategic Culture. En J. Glenn, D. Howlett y S. Poore (eds.), Neorealism versus Strategic Culture. Aldershot: Ashgate.

Porter, M. (1996). What is strategy? Harvard Business Review, November/December, 61-77.

Porter, M. (1998). Competitive Strategy: Techniques for Analyzing Industries and Competitors. Nueva York: The Free Press.

Porter, M. (2006). What is strategy? Harvard Business Review, 61-78.

Rahe, P. (2015). The Grand Strategy of Classical Sparta. New Haven: Yale University Press.

Rapaport, A. (ed.) (1968). Clausewitz: On War. Harmondsworth: Penguin.

Rattenbach, A. (1979). Introducción a la estrategia. Buenos Aires: Pleamar.

Ratzel, F. (1903). Politische Geographie. Middletown: Forgotten Books (réed. 2018).

Reclus, E. (1905) L'Homme et la Terre. París: Librairie universelle.

Ricardo, D. (1684). On the Principles of Political Economy and Taxation. Middletown: Forgotten Books (réed. 2015).

Ritter, C. (1865). Comparative Geography. Filadelfia: J. B. Lippincott y Co.

Rosen, S. (1995). Military Effectiveness: Why Society Matters. International Security, 19 (14), 5-31.

Sackmann, S. (1991). Cultural Knowledge in Organizations: Exploring the Collective Mind. Newbury Park: Sage.

Schelling, T. (1960). The Strategy of Conflict. Cambridge: Mass.

Schmidt, B. (2008). The Primacy of National Security. En S. Smith, A. Hadfield y T. Dunne (eds.), Foreign Policy: Theories, Actors, Cases. Londres: Oxford University Press.

Schmitt, C. (1963). Theorie des Partisanen. Berlín: Duncker y Humblot.

Schnaubelt, C., Larson, C. y Boyer, M. (2014). Vulnerability Assessment Method (VAM): A Tool for Center of Gravity Analysis. Santa Mónica: Rand Corporation.

Scobell, A. (2014). China's Real Strategic Culture: a Great Wall of Imagination. Contemporary Security Policy, 35 (2), 211-226.

Serrano, J. (2018). El paradigma de la guerra en el siglo XX. Revista Cientifica General José María Córdova, 16(23), 23-42. https://doi.org/10.21830/19006586.305

Sherman, W. T. (1888). The Grand Strategy of the War of the Rebellion. The Century Illustrated Monthly Magazine, 36, 597-598.

Showalter, D. (1991). Total War for Limited Objectives: An Interpretation of German Grand Strategy. En P. Kennedy (ed.), Grand Strategies in War and Peace (pp. 97-156). New Haven: Yale University Press.

Shy, J. (1986). Jomini. En P. Paret (ed.), The Makers of Modern Strategy: From Machiavelli to the Nuclear Age. Princeton: Princeton University Press.

Smith, H. (2005). On Clausewitz: A Study on Military and Political Ideas. Nueva York: Palgrave Macmillan. 
Snyder, J. (1977). The Soviet Strategic Culture: Implications for Nuclear Options. Santa Mónica: Rand Corporation.

Sokolovskiĭ, V. (1981). Estrategia militar soviética, Santiago: Ediciones Ejército.

Spykman, N. (1944). The Geography of the Peace. Nueva York. Harcourt Brace and Co.

Strachan, H. (2011). Strategy and Contingency. International Affairs, 87 (6), 1281-1296.

Strachan, H. (2013). The Direction of War: Contemporary Strategy in Historical Perspective. Cambridge: Cambridge University Press.

Strausz-Hupé, R. (1942). Geopolitics: The Struggle for Space and Power. Londres: GP Putnam's Sons.

Stone, J. (2007). Clausewitz's Trinity and Contemporary Conflict. Civil Wars, 9 (3), 282-296.

Sullivan, J. (2007). The New Great Game: Military, Police and Strategic Intelligence for Global Security. Journal of Policing, Intelligence and Counter Terrorism, 2 (2), 15-29.

Sun Tzu (2012). El arte de la guerra. Barcelona: Shambhala.

Swidler, A. (1986). Culture in Action: Symbols and Strategies. American Sociological Review, 51 (2), 273-286.

Toffler, A. (1984). The Third Wave. Nueva York: Bantam Books.

Toynbee, A. (1950). War and Civilization. Oxford: Oxford University Press.

Tse-Tung, M. (1954). On Protracted War. Pekín: People’s Publishing House.

Tucídides (1986). Historia de la guerra del Peloponeso. Barcelona: Ediciones Orbis.

Unesco. (2009). Investing in Cultural Diversity and Intercultural Dialogue. Luxemburgo: Unesco.

Vidal, P. (1921). Principes de Géographie Humaine. París: Armand Colin (réed. 1955).

Wallerstein, I. (1991). Geopolitics and Geoculture: Essays on the Changing World-System. Cambridge: Cambridge University Press.

Walt, S. (1989). The Case for Finite Containment: Analyzing U.S. Grand Strategy. International Security, 14 (1), 5-27.

Waltz, K. (1959). Man, the State, and War. Nueva York: Columbia University Press.

Waltzer, M. (1978). Just and Unjust Wars. Londres: Allen Lane.

Ward, J. (1859). A Manual of Naval Tactics: Together with a Brief Critical Analysis of the Principal Modern Naval Battles. Nueva York: D Appleton y Company.

Wendt, A. (1992). Anarchy is What States Make of it: The Social Construction of Power Politics. International Organization, 46 (2), 391-426.

Wendt, A. (1999). Social Theory of International Politics. Cambridge: Cambridge University Press.

Weygand, M. (1938). Histoire de l'Armée Française. París: Ernest Flammarion.

Wilson, R. (2000). The Many Voices of Political Culture: Assesing Different Aproaches. World Politics, 52(2), 246-273.

Wrigley, R. (1973). The American Way of War. Indiana: Indiana University Press.

Yarger, H. (2006). Toward A Theory Of Strategy: Art Lykke and the Army War College Strategy Model. Guide to National Security Policy and Strategy. Carlisle Barracks: U.S. Army War College, 107-113. 